\title{
Identification and validation of an immune-related gene pairs signature for three urologic cancers
}

\author{
Biao Xie ${ }^{1}$, Kangjie $\mathrm{Li}^{1}$, Hong Zhang ${ }^{1}$, Guichuan $\mathrm{Lai}^{1}$, Dapeng $\mathrm{Li}^{2, \&}$, Xiaoni Zhong ${ }^{1}$ \\ ${ }^{1}$ Department of Biostatistics, School of Public Health and Management, Chongqing Medical University, Chongqing, \\ China \\ ${ }^{2}$ Institute of Hepatology, National Clinical Research Center for Infectious Disease, Shenzhen Third People's \\ Hospital, Shenzhen, China
}

Correspondence to: Dapeng Li, Xiaoni Zhong; email: Idroc@163.com, https://orcid.org/0000-0001-5207-0498;

zhongxiaoni@cqmu.edu.cn

Keywords: urologic cancer, bladder cancer, prostate cancer, kidney cancer, immune-related gene pairs

Received: October 25, $2021 \quad$ Accepted: January 25, $2022 \quad$ Published: February 10, 2022

Copyright: (C) 2022 Xie et al. This is an open access article distributed under the terms of the Creative Commons Attribution License (CC BY 3.0), which permits unrestricted use, distribution, and reproduction in any medium, provided the original author and source are credited.

\section{ABSTRACT}

Reliable biomarkers are needed to recognize urologic cancer patients at high risk for recurrence. In this study, we built a novel immune-related gene pairs signature to simultaneously predict recurrence for three urologic cancers. We gathered 14 publicly available gene expression profiles including bladder, prostate and kidney cancer. A total of 2,700 samples were classified into the training set $(n=1,622)$ and validation set $(n=1,078)$. The 25 immunerelated gene pairs signature consisting of 41 unique genes was developed by the least absolute shrinkage and selection operator regression analysis and Cox regression model. The signature stratified patients into high- and low-risk groups with significantly different relapse-free survival in the meta-training set and its subpopulations, and was an independent prognostic factor of urologic cancers. This signature showed a robust ability in the metavalidation and multiple independent validation cohorts. Immune and inflammatory response, chemotaxis and cytokine activity were enriched with genes relevant to the signature. A significantly higher infiltration level of M1 macrophages was found in the high-risk group versus the low-risk group. In conclusion, our signature is a promising prognostic biomarker for predicting relapse-free survival in patients with urologic cancer.

\section{INTRODUCTION}

Bladder cancer, prostate cancer and kidney cancer are the main tumors in the urinary system, and nearly 2.4 million new cases are diagnosed each year [1]. The advance of targeted therapy and neoadjuvant therapy has prolonged the survival of patients [2-4]. However, numerous patients suffer relapses even after complete surgical resection [5-7], and their prognoses are still not optimistic. A reliable prognostic biomarker which could identify patients with a higher risk for relapse and select patients who have response to therapies would be valuable for management of urologic cancers.

Gene-expression signatures have been identified for survival stratification of bladder cancer $[8,9]$, prostate cancer $[10,11]$ and kidney cancer $[12,13]$. However, most biomarkers have not been translated to clinical practice due to over-fitting of training datasets or lack of sufficient validation [14]. A chance to develop more reliable prognostic biomarkers has been brought by sufficient large-scale public gene expression datasets [15, 16]. However, it is a challenge to integrate data derived from different platforms. The traditional method has made it difficult to normalize different datasets, given technical biases and biological heterogeneity of multiple platforms $[17,18]$. New methods based on the relative ranking of gene expression levels have been used to eliminate the requirement for data preprocessing, and have attained robust results in many applications [19-21].

Increasing evidence has indicated that the tumor immune microenvironment is correlated with the formation and progression of the three main urologic tumors [22-24]. 
The immune checkpoint molecules, such as programmed cell death 1 (PD-1), PD-1 ligand 1 (PD-L1) and cytotoxic T-lymphocyte associated antigen 4 (CTLA-4), have demonstrated a remarkable, durable response in bladder cancer [25, 26], prostate cancer [27, 28] and kidney cancer $[29,30]$. The biomarkers related with the tumor immune microenvironment may thus have potential as prognostic markers of urologic cancers.

As is well-known, bladder cancer, prostate cancer and kidney cancer are closely related anatomically and result from similar insults that promote tumor formation [31-33]. Therefore, we have developed in this study a signature based on immune-related gene pairs (IRGPs) to simultaneously predict the recurrence of bladder cancer, prostate cancer and kidney cancer.

\section{MATERIALS AND METHODS}

\section{Study design and datasets}

We comprehensively analyzed 14 gene expression profiles in three urologic tumors of bladder, prostate and kidney cancer, including seven microarray datasets and seven RNA-Seq datasets (Supplementary Figure 1). The accession numbers, platforms and samples sizes of these gene expression profiles are shown in Supplementary Table 1. RNA-Seq data were downloaded from UCSC Xena (http://xena.ucsc.eduaccessed on January 2021) and the International Cancer Genome Consortium (ICGC) (https://dcc.icgc.org/projects). Microarray data were downloaded from the Gene Expression Omnibus (GEO) (http://www.ncbi.nlm.nih.gov/geo). Cohorts from The Cancer Genome Atlas (TCGA) were used as the training set, and other datasets were used as the validation set. Only patients with complete survival information were included. We also excluded patients who had received radiation therapy, neoadjuvant therapy and targeted molecular therapy in all independent training cohorts. In total, 2,700 cases were included in our study. Our project was approved by Chongqing Medical University's Ethical Review Committee.

\section{Gene expression data processing}

The publicly available datasets from GEO were firstly normalized using the normalizeBetweenArrays function as implemented in the 'limma' package, and then were further log-transformed. Normalization methods were not used in TCGA and ICGC cohorts.

\section{Identification of specific IRGPs for prognosis prediction}

We downloaded immune-related genes (IRGs) from the ImmPort database (https://immport.niaid.nih.gov) accessed on 3/3/2021. 2,483 unique IRGs, constituting 17 categories, including cytokines, cytokine receptors, antigen processing, presentation pathways, interleukins, natural killer cell cytotoxicity, TGFb and TNF family members. Only IRGs measured by all platforms with a median absolute deviation $>0.5$ in all independent training sets were chosen. The score for each IRGP was generated by pairwise comparisons of the gene expression level in a certain sample of profiles. The IRGPs score was defined as 1 if expression level of IRG 1 was larger than IRG 2; otherwise, the IRGPs score was set as 0 [34]. After removing IRGPs with constant values in any individual dataset, the remaining IRGPs were further analyzed.

\section{Construction of the immune-related gene pairs index (IRGPI) for prognosis prediction}

Prognostic IRGPs were selected based on the following steps. Firstly, the predictive ability of each IRGP predicting patients' relapse-free survival (RFS) was evaluated by using the Cox regression model in the meta-training dataset, and the IRGPs with a p-value < 0.05 were selected as initial candidate markers. Secondly, the least absolute shrinkage and selection operator (LASSO) analysis was utilized to further filter out some less informative IRGPs. The tuning parameter was determined by the expected generalization error estimated from 10-fold cross-validation. To improve robustness, we randomly split the full meta-training dataset into new training and testing datasets with a 2:1 ratio, and repeated the random split scheme 30 times to stabilize the IRGPs selection procedure. The LASSO model was then applied to the 30 training sets, and those IRGPs with a frequency > 15 were selected. Finally, the multivariate Cox regression model was used to build the IRGPs-based prediction model and generate the IRGPI for all samples. The patients were classified into low and high immune risk groups using the median IRGPI value.

\section{Evaluation and validation of the IRGPI}

The prognostic value of the IRGPI was evaluated in the meta-training and independent training sets, and was further verified in the meta-validation and multiple independent validation sets. The log-rank test and time-dependent receiver operating characteristic (ROC) curves were adopted to assess the prognostic accuracy of the IRGPI. We combined IRGPI with clinical factors of age, gender and tumor stage in multivariate Cox analyses. Age ( $>60)$ was transformed into 1 , age $(<60)$ was transformed into 0 . Stage III and IV were transformed into 1 , stage I and II were transformed into 0 . 


\section{Profiling of infiltrating immune cells}

CIBERSORT characterizes immune cell composition by using bulk-tumor gene expression profiles [35]. It inferred the relative proportions of 22 types of infiltrating immune cells based on the reference gene expression values (LM22) [35]. In this study, the proportions of 22 infiltrating immune cells were determined by using the $\mathrm{R}$ package 'CIBERSORT'. The perm was set at 1,000 , and cases with a CIBERSORT output p-value $<0.05$ were selected for further analysis. The Wilcoxon rank sum test was utilized to compare differences in immune cell subtypes between the high and low IRGPI groups.

\section{Gene ontology (GO) analysis}

The R package 'clusterProfiler' was utilized to conduct GO enrichment analysis of the genes related to the IRGPI in the meta-training cohort. The BenjaminiHochberg-adjusted p-value $<0.05$ (false discovery rate, FDR) was used as the threshold to determine significance.

\section{Construction and evaluation of the nomogram}

A nomogram was constructed to establish a quantitative approach for RFS prediction in the meta-training cohort based on the IRGPI and clinical factors, which was further verified in the meta-validation cohorts. A point was calculated for each factor, and the total points of all factors were then obtained for the estimation of RFS rates at $1,3,5$, and 10 years. The calibration plots were then drawn to evaluate the reliability of the nomogram.

\section{Statistical analysis}

The $\mathrm{R}$ package 'survival', 'glmnet', 'survminer', 'timeROC', 'rms', 'CIBERSORT' and 'clusterProfiler' were used to construct the Cox regression model, LASSO model, Kaplan-Meier curve, time-dependent ROC curve, nomogram, immune cell composition computation and GO analysis. The association of IRGPI score with RFS was analyzed by log-rank test. The Cox regression model was adopted to perform multivariate analysis of the association of IRGPI with RFS. A twosided p-value $<0.05$ was considered statistically significant for all tests. All statistical analyses were conducted using $\mathrm{R}$ (version 4.0.2).

\section{RESULTS}

\section{Establishing and evaluating the IRGPI}

A total of 2,700 patients with three urologic cancers, including 835 bladder cancer, 888 prostate cancer and
977 kidney cancer patients, were included in this study (Supplementary Table 1). As shown in Supplementary Figure 1, 1,622 patients in TCGA cohorts were used as the meta-training dataset. Another 1,078 patients from seven GEO datasets and two ICGC datasets constituted the meta-validation dataset. Among 2,483 IRGs from the ImmPort database, 606 IRGs were measured on all platforms and met the criteria (MAD > 0.5) on all independent training sets. Based on 606 IRGs, 183,315 IRGPs were constructed. After removing those not shared among all datasets or with constant ordering in any data set, 18,041 IRGPs were left and selected for further analysis. First, 10,943 IRGPs were filtered out by using the univariate Cox regression model in the meta-training data set. To further screen candidate IRGPs, LASSO was conducted 30 times to select those which appeared more than 15 times out of 30 analyses. As a result, 25 IRGPs and 41 unique IRGs were selected (Supplementary Table 2). The multivariate Cox regression model was then used to obtain the IRGPsbased prediction model and generate IRGPI scores for all samples. The patients in the meta-training cohort were classified into low and high immune risk groups by using the median IRGPI (-1.216973). There were significantly different prognoses in terms of RFS between low- and high-risk groups in the meta-training cohort (Figure 1A, hazard ratio [HR] 6.078, 95\% confidence interval [CI] 4.754-7.769; $\left.P<2 \times 10^{-16}\right)$. The IRGPI could also divided patients into subgroups with significantly different RFS in the training cohort of bladder cancer (Figure 1B, HR 2.308, 95\% CI 1.6603.210; $P=3 \times 10^{-7}$ ), prostate cancer (Figure 1C, HR 3.054, 95\% CI 1.778-5.245; $P=2 \times 10^{-5}$ ) and kidney cancer (Figure 1D, HR 5.582, 95\% CI 3.899-7.992; $P<$ $\left.2 \times 10^{-16}\right)$. The time-dependent ROC curves were used to evaluate the ability of the IRGPI to predict prognosis. The area under the curve (AUC) values in predicting 1-, 3-, 5- and 10-year RFS of patients were 0.816, 0.818, 0.828 , and 0.763 , respectively, in the meta-training cohort (Supplementary Figure 2A). When patients were stratified by different tumor stages, genders and age groups, low and high IRGPI groups remained significantly different for RFS, and a higher IRGPI score was associated with significantly worse prognosis (Figure 2). The patients with high IRGPI and advanced tumor stage had the highest RFS among all patients in the meta-training cohort (Supplementary Figure 2B). Multivariate analyses suggested that the IRGPI was an independent prognostic factor (HR 4.22, 95\% CI 3.235.52; $\left.P<2 \times 10^{-16}\right)$ after adjusting for age and stage (Supplementary Table 3 ).

\section{Validation of the IRGPI}

External validation cohorts were used to confirm the ability of the IRGPI to predict RFS of patients with 

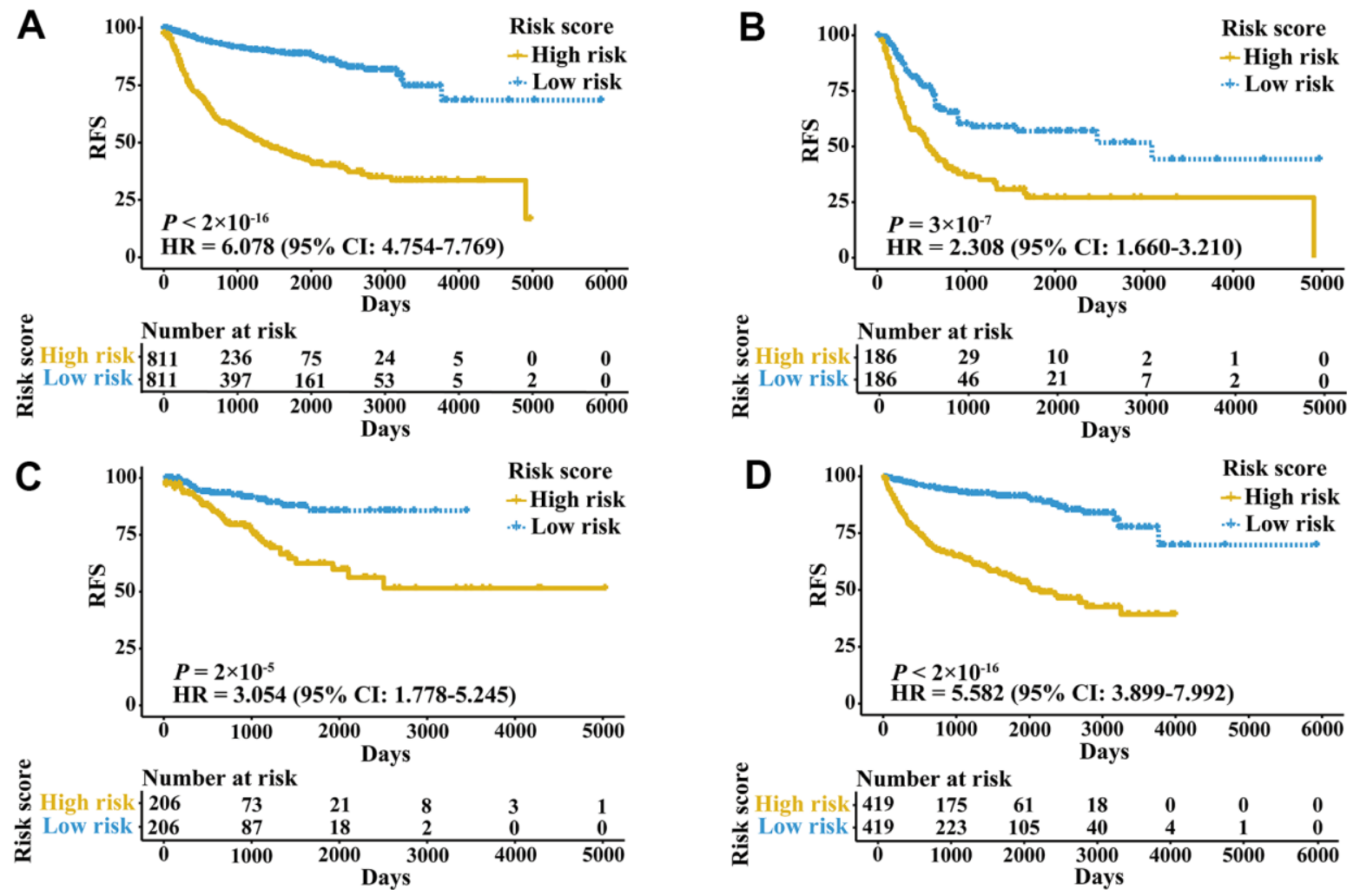

Figure 1. Kaplan-Meier curves of patients in training cohorts stratified by the IRGPI. (A) RFS among patients in the meta-training cohort. (B) RFS among patients in the training cohort of bladder cancer. (C) RFS among patients in the training cohort of prostate cancer. (D) RFS among patients in the training cohort of kidney cancer. HRs and $95 \% \mathrm{Cls}$ are shown for high vs low immune risk. $P$ values comparing risk groups were calculated by the log-rank test.
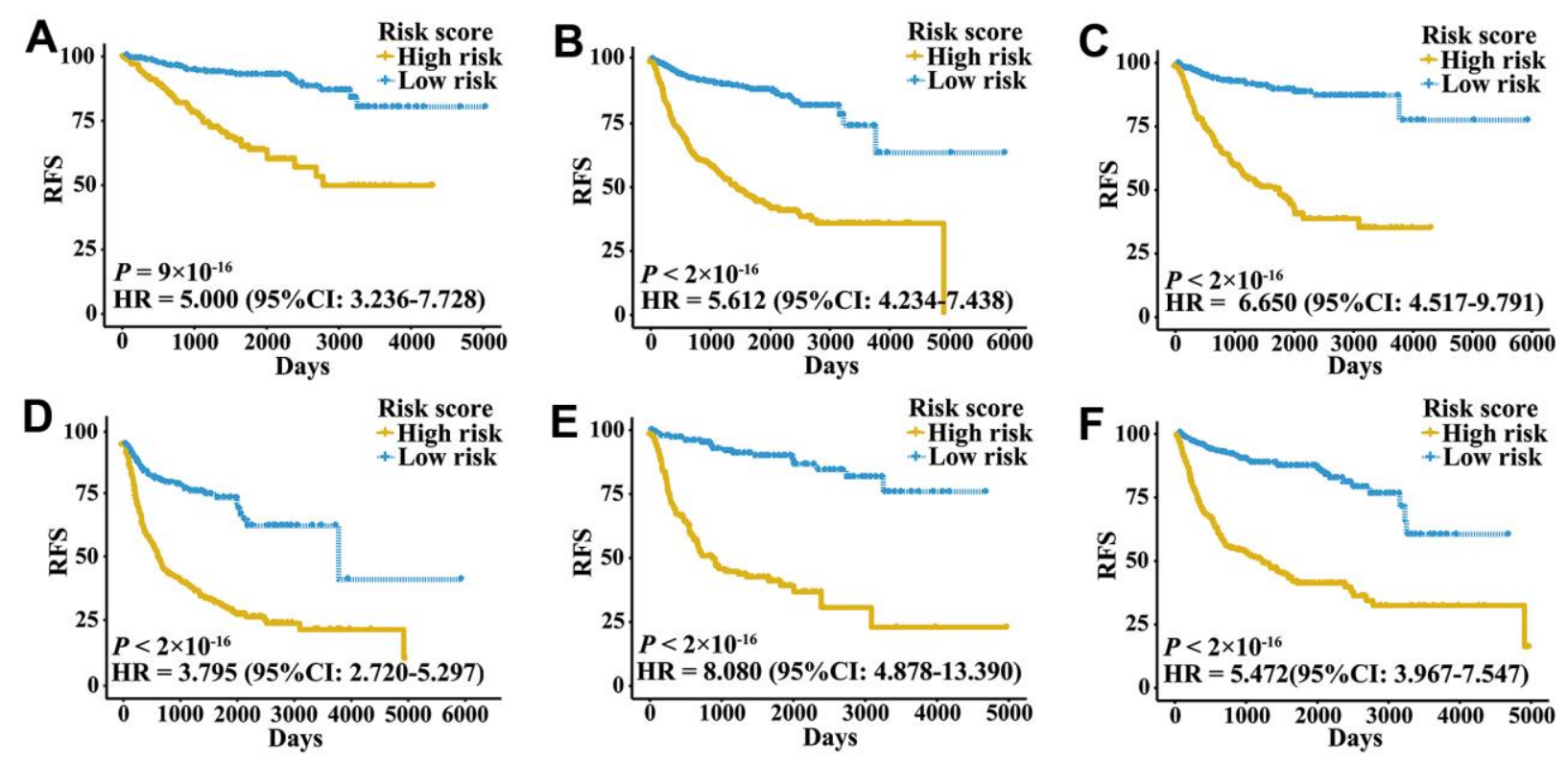

Figure 2. Kaplan-Meier curves of patients with different clinical factors in the meta-training cohort. (A) RFS among patients with early-stage disease. (B) RFS among male patients. (C) RFS among patients younger than 60 years. (D) RFS among patients with late-stage disease. (E) RFS among female patients. (F) RFS among patients older than 60 years. 
three urologic cancers in different populations. The same IRGPs were used to calculate the IRGPI, and the patients were also classified into low- and high-risk groups. RFS of patients in low and high IRGPI groups were significantly different in the meta-validation cohort (Figure 3A, HR 3.326, 95\% CI 2.623-4.217; $\left.P<2 \times 10^{-16}\right)$, validation dataset of bladder cancer (Figure 3B, HR 3.987, 95\% CI 2.641-6.019; $P=1 \times 10^{-}$ ${ }^{12}$ ), validation dataset of prostate cancer (Figure 3C, HR $3.277,95 \%$ CI $2.275-4.719 ; P=2 \times 10^{-11}$ ), and validation dataset of kidney cancer (Figure 3D, HR $2.523,95 \%$ CI $\left.1.529-4.165 ; P=2 \times 10^{-4}\right)$. Time-ROC curves showed stable predictive abilities, with 1-, 3-, 5-, and 10-year AUCs of 0.794, 0.764, 0.739, and 0.605, respectively (Supplementary Figure 2C). Similarly, the patients with high IRGPI and advanced tumor stage had the highest RFS among patients in the meta-validation cohort (Supplementary Figure 2D). Consistent with the training cohorts, the IRGPI was able to divide patients into significantly different groups in terms of RFS in mostly independent validation cohorts (Supplementary
Figure 3). When considering patients with early- or latestage disease, male patients and patients older than 60 years, the IRGPI remained highly prognostic, and a higher IRGPI score was associated with significantly worse prognosis (Figure 4). After adjusting for age and stage in Cox regression analyses, the IRGPI remained as an independent prognostic factor in the metavalidation cohort (HR 2.15, 95\% CI 1.45-3.19; $P=$ 0.000149; Supplementary Table 3).

\section{Functional analysis and infiltrating immune content related to the IRGPI}

The 41 unique IRGs relevant to the IRGPI in the metatraining cohort were mainly involved in the immune and inflammatory response, cytokine activity and chemotaxis (Supplementary Table 4 and Figure 5). Various immune infiltrates were enriched in the metatraining cohort, and Macrophages M2, T cells CD8, T cells CD4 memory resting, Macrophages M0 and Macrophages M1 showed higher abundance
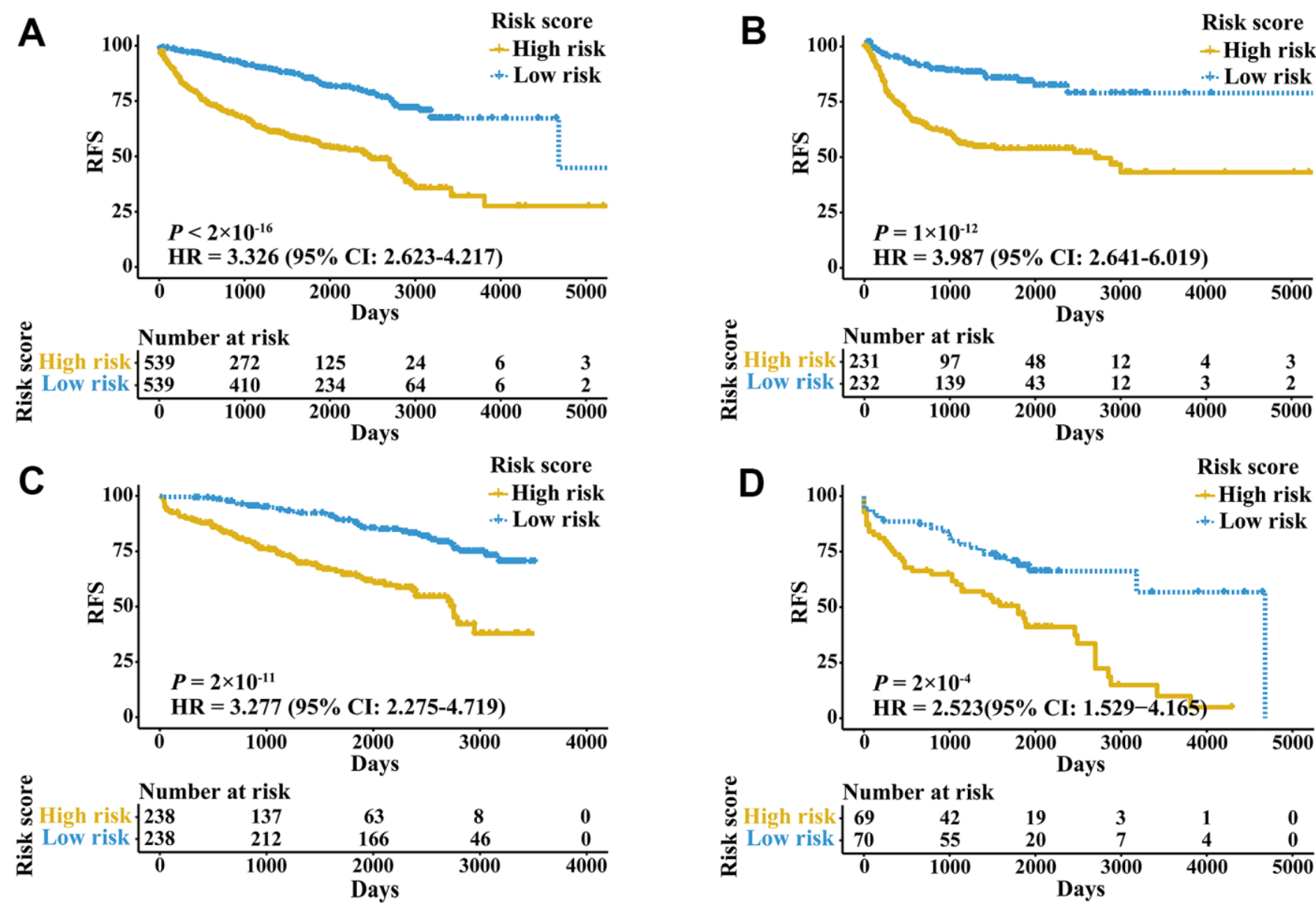

Figure 3. Kaplan-Meier curves of patients in validation cohorts stratified by the IRGPI. (A) RFS among patients in the metavalidation cohort. (B) RFS among patients in the validation cohort of bladder cancer. (C) RFS among patients in the validation cohort of prostate cancer. (D) RFS among patients in the validation cohort of kidney cancer. 

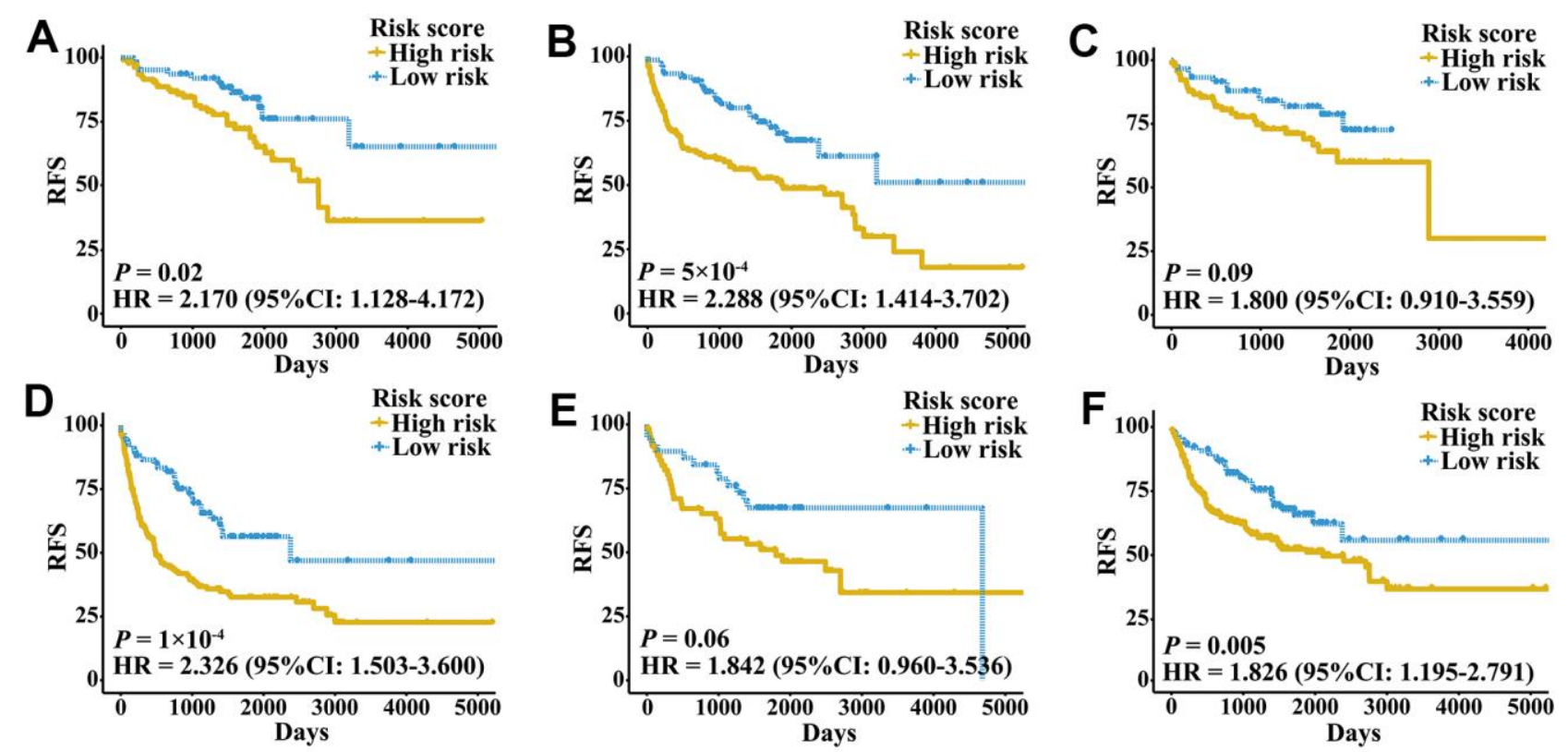

Figure 4. Kaplan-Meier curves of patients with different clinical factors in the meta-validation cohort. (A) RFS among patients with early-stage disease. (B) RFS among male patients. (C) RFS among patients younger than 60 years. (D) RFS among patients with late-stage disease. (E) RFS among female patients. (F) RFS among patients older than 60 years.

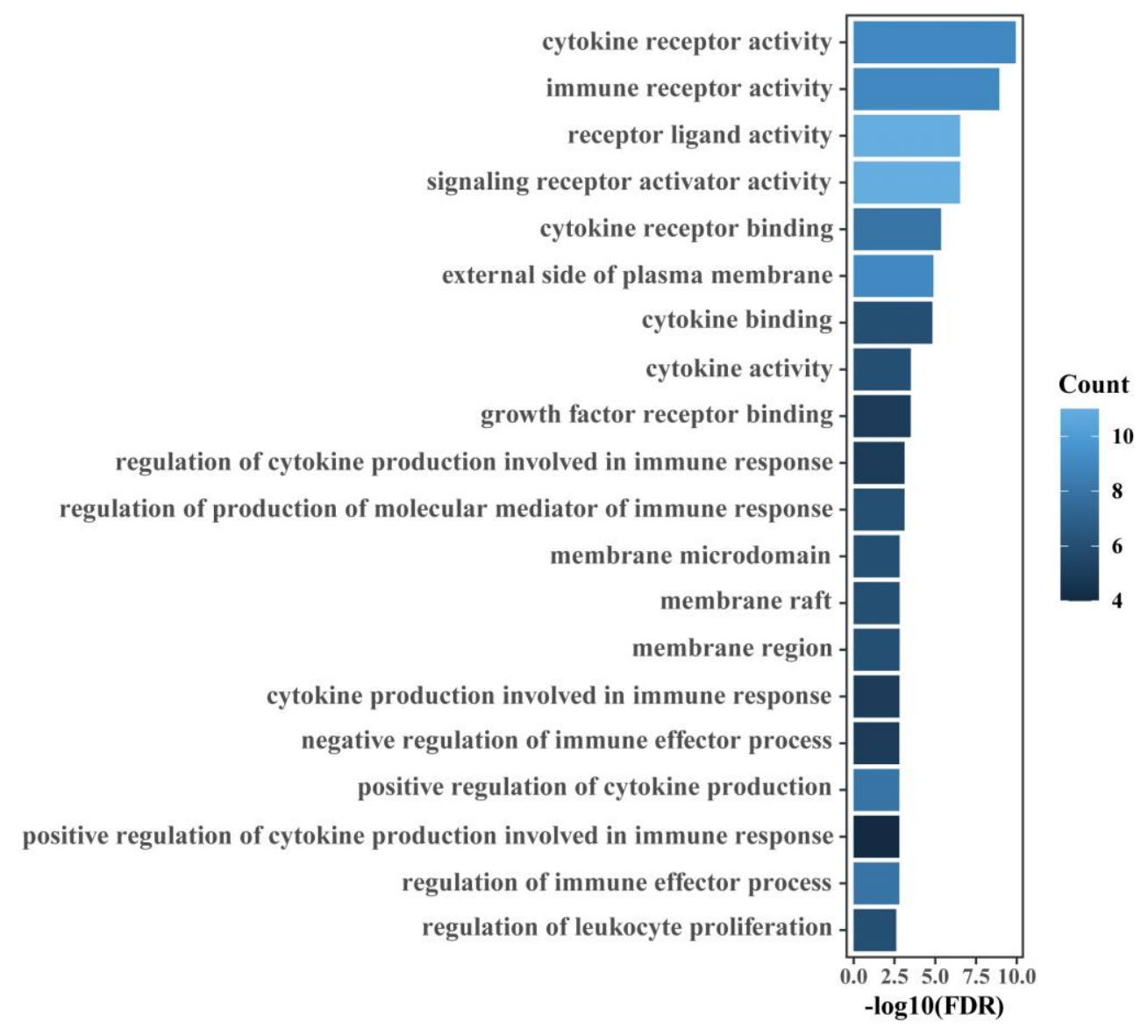

Figure 5. GO enrichment analyses of IRGs relevant to the IRGPI. The top 20 GO terms ranked by FDR are listed. 
(Figure 6A). Among those, percentages of Macrophages M0, Macrophages M1 and macrophage M2 were significantly different between IRGPI risk groups (Figure 6B). Furthermore, those results were validated in the meta-validation cohorts in which the same five immune infiltrates with higher immune cell abundance were enriched (Figure 6C). The percentages of Macrophages M1 and macrophage M2 were also significantly different between IRGPI risk groups (Figure 6D).

\section{Nomogram based on the IRGPI and clinical factors}

Univariate Cox regression analysis showed that age, stage and IRGPI score were significant predictors of prognosis (Supplementary Table 3). To establish a
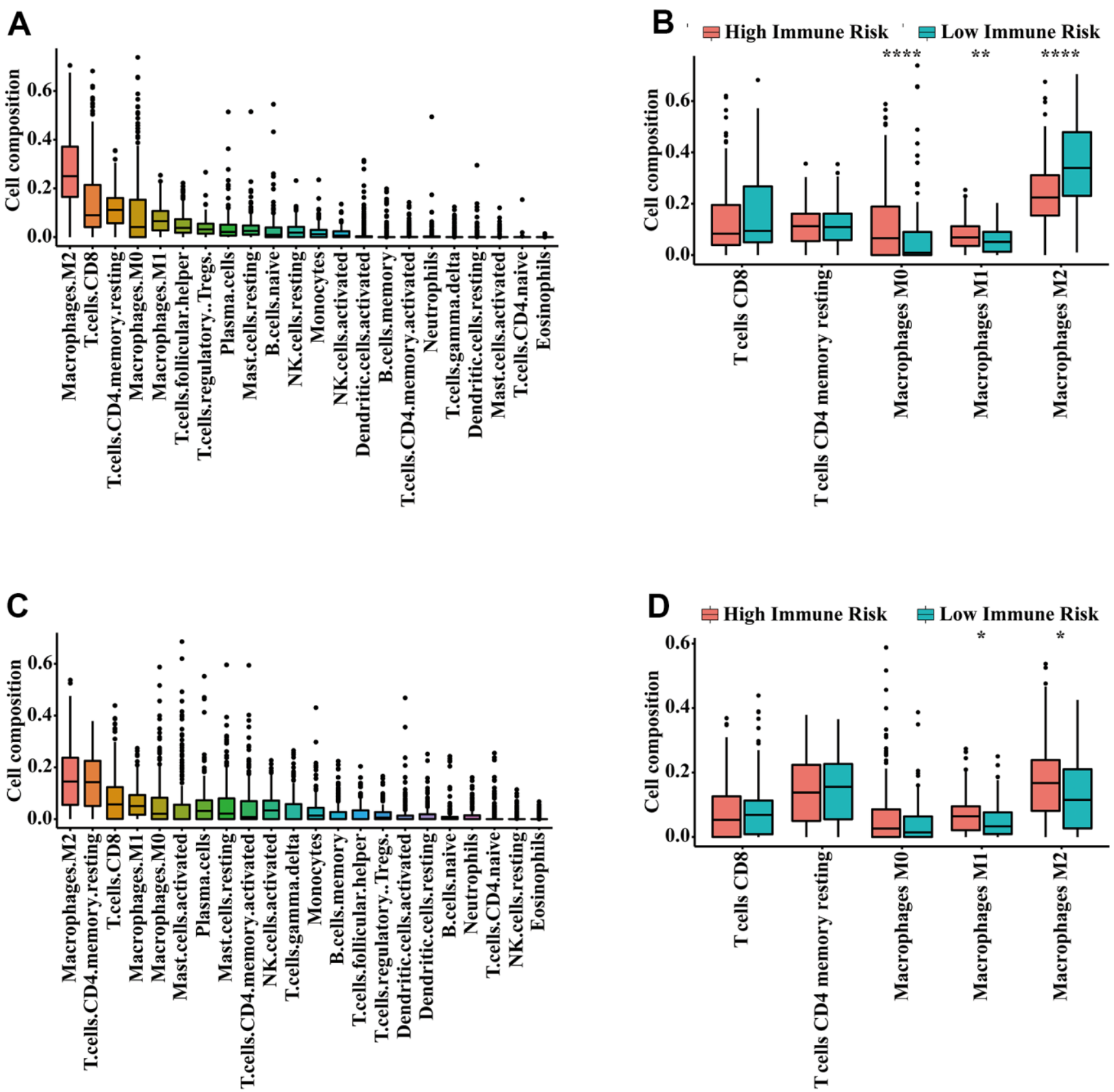

Figure 6. Infiltrating immune content related to the IRGPI. (A) The abundance of 22 immune cells in the meta-training cohort. (B) Immune cell abundance within each risk group in the meta-training cohort. The top five immune cells ranked by abundance are contrasted. (C) The abundance of 22 immune cells in the meta-validation cohort. (D) Immune cell abundance within each risk group in the metavalidation cohort. The top five immune cells ranked by abundance were contrasted. P-values were calculated with the Wilcoxon test (*P<0.05, ** $P<0.01, * * * P<0.001)$. 
quantitative approach for RFS prediction, we performed a nomogram based on prognostic factors (IRGPI, age, and stage) in the meta-training and meta-validation sets (Figure 7A, 7B). The reliability of the nomograms was evaluated by the calibration plot. As a result, the linesegments in the calibration plots were close to the $45^{\circ}$ line, indicating an excellent agreement between the prediction and observation in the meta-training cohort (Supplementary Figure 4A-4D) and meta-validation cohort (Supplementary Figure 4E-4H).

\section{DISCUSSION}

In this study, we developed a signature based on 25 IRGPs to simultaneously predict the prognosis of urinary cancer, including bladder, prostate, and kidney cancer. The signature showed a robust ability for predicting RFS of urinary cancers in training cohorts and multiple validation cohorts. Our signature could also distinguish different RFS in defined groups of patients (e.g., early-stage) in stratified analyses. The constructed nomogram based on the IRGPI score and clinical prognostic factors was able to quantitatively predict RFS rates of bladder, prostate and kidney cancer patients.

Patients with bladder [36], prostate [37] and kidney cancer [38] have substantial risk for relapse, even after surgical resection. The use of various adjuvant therapies, particularly in early-stage patients, remains disputable [39]. Reliable prognostic biomarkers are urgently needed to identify patients with a higher risk for relapse and select patients who have response to therapies. Many signatures based on gene expression were developed to predict the prognosis of bladder [4042], prostate [43-45] and kidney cancer [46-48]. However, the common drawback in those studies were technical biases caused by the normalization of expression profiles derived from different platforms using RNA-Seq or microarrays. Based on the relative ranking of gene expression, the IRGPs signature in the present study focused on pairwise comparisons within the gene expression profile of samples. The need for data normalization was eliminated to the utmost extent, and technical biases between different platforms when combining multiple gene expression profiles were avoided. A few researchers have identified IRGPs signatures related to the prognosis of urinary cancer patients; for example, Fu et al. found a novel IRGPs signature that had significant prognostic value in predicting overall survival in bladder cancer [49]. Researchers in southern China have also developed an IRGPs to predict the prognosis of patients with papillary renal cell carcinoma [50]. However, these studies lacked sufficient validation due to the relatively small sample size, and could only predict the prognosis of single tumor. In this study, we integrated large-scale datasets from multiple platforms to identify the IRGPs signature. The signature could simultaneously predict RFS of three main urologic tumors, and was robust after being verified. Therefore, our signature can be expediently promoted to clinical usage.

The tumor immune microenvironment has been shown to be correlated with prognosis of bladder [22, 51], prostate [23, 52] and kidney cancer [24, 53]. In the era of immunotherapy, prognostic biomarkers relevant to the tumor immune microenvironment may break a new path for identifying novel prognostic biomarkers. In this study, most of the IRGs involved in our immune signature were cytokines, antimicrobials and cytokine receptors, which are closely related to immune response and inflammatory processes. Enrichment analysis also indicated that the IRGs relevant to the immune
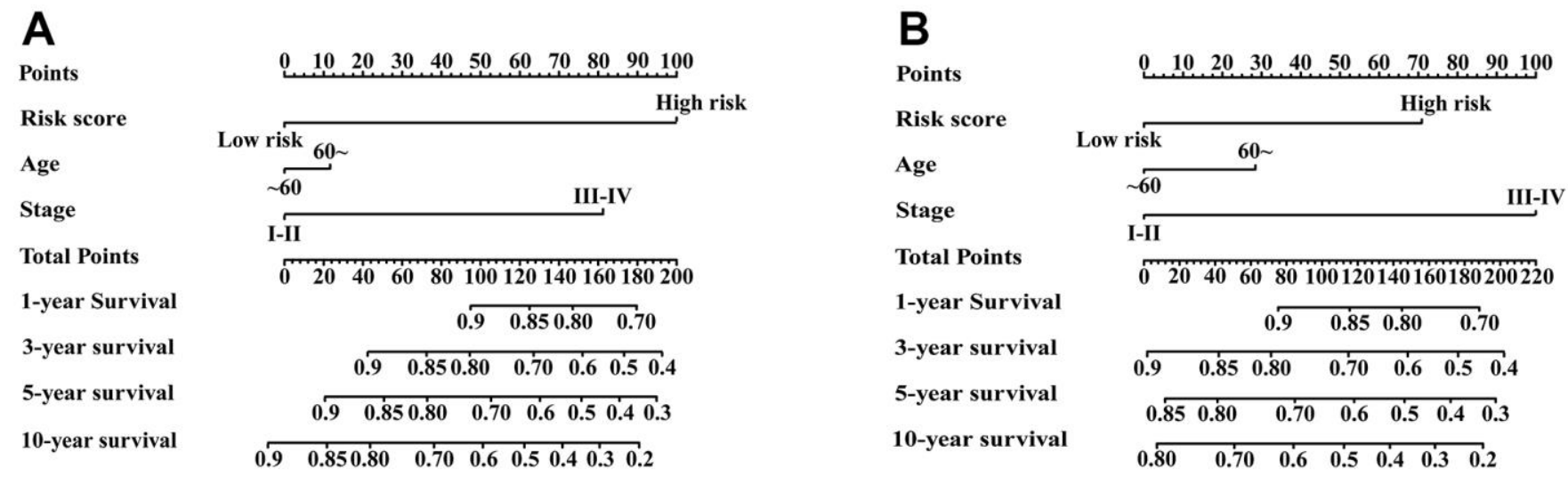

Figure 7. Nomograms constructed for predicting 1-, 3-, 5-, and 10-year RFS. (A) Nomograms predicting 1-, 3-, 5- and 10-year RFS rates among patients in the meta-training set. (B) Nomograms predicting 1-, 3-, 5- and 10-year RFS rates among patients in the metavalidation set. 
signature were mainly involved in the immune and inflammatory response and cytokine activity. An increased inflammatory microenvironment was found in the main tumors of the urinary system. This finding was consistent with previous studies showing that the formation and progression of tumors were related to an increased inflammatory microenvironment [54, 55]. Diverse immune cells such as neutrophils and macrophages are involved in the inflammatory response process of tumors. Macrophages have been shown to be correlated with poor prognosis in many cancers $[56,57]$. In the present study, we found the infiltration level of macrophage $\mathrm{M} 1$ in the immune high-risk group significantly increased. It is possible that the dysregulated immune contexture may result in the survival differences observed between risk groups as defined by the IRGPI. Noteworthily, the infiltration level of M1 macrophages in the high-risk and low-risk group are inconsistent in researches [49, 50, 58-61]. Of these studies, two of them are consistent with our result $[50,58]$, three of them report that there is no significant difference [59-61], and only one research is contrary to ours [49]. The inconsistencies in the infiltration level of M1 macrophages may be related to study population differences, that is, the samples that generate risk scores are different.

To note, there were limitations in this study. Firstly, the 25 IRGPs prognostic signature was based on a retrospective study, although nine datasets were used for rigorous validation. Our results should be further validated in prospective cohorts with different sample attributes. Secondly, our prognostic signature also needs to be validated by quantitative real-time polymerase chain reaction before it can be applied clinically. Thirdly, we removed IRGPs with constant values to reduce the influence of batch effects between different platforms, but batch effects cannot be completely eliminated.

In conclusion, our 25 IRGPs signature is a promising and robust prognostic biomarker for predicting the RFS of bladder, prostate, and kidney cancer, including earlystage cancers. Moreover, this signature was associated with the infiltration of immune cell subsets and immune response, indicating the associations between the immune microenvironment and those cancers, and hence could help to formulate personalized immunotherapy strategy. Although the clinical utility of our signature needs to be validated in prospective studies, our study has nonetheless provided a panel of promising prognostic markers by integrating large-scale datasets.

\section{AUTHOR CONTRIBUTIONS}

$\mathrm{XZ}$ and DL designed this study. KL, HZ and GL analyzed relevant data. BX wrote the manuscript. All authors reviewed the final manuscript.

\section{CONFLICTS OF INTEREST}

The authors declare that they have no conflicts of interest.

\section{FUNDING}

The National Science and Technology Major Project of the Ministry of Science and Technology of China (2018ZX10721102005) and Postdoctoral Science Foundation of Chongqing.

\section{Editorial note}

\&This corresponding author has a verified history of publications using a personal email address for correspondence.

\section{REFERENCES}

1. Sung $H$, Ferlay J, Siegel RL, Laversanne $M$, Soerjomataram I, Jemal A, Bray F. Global Cancer Statistics 2020: GLOBOCAN Estimates of Incidence and Mortality Worldwide for 36 Cancers in 185 Countries. CA Cancer J Clin. 2021; 71:209-49.

https://doi.org/10.3322/caac. 21660 PMID:33538338

2. Seiler $\mathrm{R}$, Oo $\mathrm{HZ}$, Tortora $\mathrm{D}$, Clausen $T M$, Wang $C K$, Kumar G, Pereira MA, Ørum-Madsen MS, Agerbæk M $\varnothing$, Gustavsson T, Nordmaj MA, Rich JR, Lallous N, et al. An Oncofetal Glycosaminoglycan Modification Provides Therapeutic Access to Cisplatin-resistant Bladder Cancer. Eur Urol. 2017; 72:142-50. https://doi.org/10.1016/i.eururo.2017.03.021 PMID:28408175

3. Maroto P, Solsona E, Gallardo E, Mellado B, Morote J, Arranz JÁ, Gómez-Veiga F, Unda M, Climent MÁ, Alcaraz A. Expert opinion on first-line therapy in the treatment of castration-resistant prostate cancer. Crit Rev Oncol Hematol. 2016; 100:127-36. https://doi.org/10.1016/i.critrevonc.2015.07.011 PMID:26363809

4. Fu $Q, X u L$, Wang $Y$, Jiang $Q$, Liu Z, Zhang J, Zhou $Q$, Zeng $\mathrm{H}$, Tong S, Wang T, Qi Y, Hu B, Fu H, et al. Tumorassociated Macrophage-derived Interleukin-23 Interlinks Kidney Cancer Glutamine Addiction with Immune Evasion. Eur Urol. 2019; 75:752-63. https://doi.org/10.1016/i.eururo.2018.09.030 PMID:30293904

5. Zhao Z, Wang Y, Zhang JJ, Huang XY. Fascin Inhibitors Decrease Cell Migration and Adhesion While Increase Overall Survival of Mice Bearing Bladder Cancers. Cancers (Basel). 2021; 13:2698. https://doi.org/10.3390/cancers13112698 
PMID: $\underline{34070777}$

6. Peltomaa Al, Raittinen P, Talala K, Taari K, Tammela TL, Auvinen A, Murtola TJ. Prostate cancer prognosis after initiation of androgen deprivation therapy among statin users. A population-based cohort study. Prostate Cancer Prostatic Dis. 2021; 24:917-24. https://doi.org/10.1038/s41391-021-00351-2 PMID: $\underline{3790420}$

7. Tian M, Wang T, Wang P. Development and Clinical Validation of a Seven-Gene Prognostic Signature Based on Multiple Machine Learning Algorithms in Kidney Cancer. Cell Transplant. 2021; 30:963689720969176. https://doi.org/10.1177/0963689720969176 PMID:33626918

8. Zhang C, Gou X, He W, Yang H, Yin H. A glycolysis-based 4-mRNA signature correlates with the prognosis and cell cycle process in patients with bladder cancer. Cancer Cell Int. 2020; 20:177. https://doi.org/10.1186/s12935-020-01255-2 PMID:32467671

9. Chen S, Zhang N, Shao J, Wang T, Wang X. A novel gene signature combination improves the prediction of overall survival in urinary bladder cancer. J Cancer. 2019; 10:5744-53. https://doi.org/10.7150/jca.30307 PMID:31737111

10. Xu Z, Xu L, Liu L, Li H, Jin J, Peng M, Huang Y, Xiao H, Li Y, Guan H. A Glycolysis-Related Five-Gene Signature Predicts Biochemical Recurrence-Free Survival in Patients With Prostate Adenocarcinoma. Front Oncol. 2021; 11:625452.

https://doi.org/10.3389/fonc.2021.625452

PMID:33954109

11. Nguyen HT, Xue H, Firlej V, Ponty $Y$, Gallopin $M$, Gautheret D. Reference-free transcriptome signatures for prostate cancer prognosis. BMC Cancer. 2021; 21:394.

https://doi.org/10.1186/s12885-021-08021-1 PMID:33845808

12. Lu J, Qian C, Ji Y, Bao Q, Lu B. Gene Signature Associated With Bromodomain Genes Predicts the Prognosis of Kidney Renal Clear Cell Carcinoma. Front Genet. 2021; 12:643935.

https://doi.org/10.3389/fgene.2021.643935

PMID:34149798

13. Wu Y, Wei X, Feng H, Hu B, Liu B, Luan Y, Ruan Y, Liu X, Liu Z, Liu J, Wang T. Integrated Analysis to Identify a Redox-Related Prognostic Signature for Clear Cell Renal Cell Carcinoma. Oxid Med Cell Longev. 2021; 2021:6648093.

https://doi.org/10.1155/2021/6648093

PMID:33968297

14. Shi R, Bao X, Unger K, Sun J, Lu S, Manapov F, Wang X,
Belka C, Li M. Identification and validation of hypoxiaderived gene signatures to predict clinical outcomes and therapeutic responses in stage I lung adenocarcinoma patients. Theranostics. 2021; 11:5061-76.

https://doi.org/10.7150/thno.56202 PMID:33754044

15. Brendel M, Barthel $H$, van Eimeren $T$, Marek K, Beyer $L$, Song M, Palleis C, Gehmeyr M, Fietzek U, Respondek G, Sauerbeck J, Nitschmann A, Zach C, et al. Assessment of $18 \mathrm{~F}-\mathrm{PI}-2620$ as a Biomarker in Progressive Supranuclear Palsy. JAMA Neurol. 2020; 77:1408-19. https://doi.org/10.1001/jamaneurol.2020.2526 PMID:33165511

16. Lee ES, Jung SY, Kim JY, Kim JJ, Yoo TK, Kim YG, Lee KS, Lee ES, Kim EK, Min JW, Han W, Noh DY, Moon HG. Identifying the potential long-term survivors among breast cancer patients with distant metastasis. Ann Oncol. 2016; 27:828-33.

https://doi.org/10.1093/annonc/mdw036 PMID:26823524

17. Franks JM, Cai G, Whitfield ML. Feature specific quantile normalization enables cross-platform classification of molecular subtypes using gene expression data. Bioinformatics. 2018; 34:1868-74. https://doi.org/10.1093/bioinformatics/bty026 PMID:29360996

18. Shen $Y$, Rahman M, Piccolo SR, Gusenleitner D, ElChaar NN, Cheng L, Monti S, Bild AH, Johnson WE. ASSIGN: context-specific genomic profiling of multiple heterogeneous biological pathways. Bioinformatics. 2015; 31:1745-53.

https://doi.org/10.1093/bioinformatics/btv031 PMID:25617415

19. Wu J, Zhao Y, Zhang J, Wu Q, Wang W. Development and validation of an immune-related gene pairs signature in colorectal cancer. Oncoimmunology. 2019; 8:1596715. https://doi.org/10.1080/2162402X.2019.1596715 PMID:31143520

20. Xu F, Zhan X, Zheng X, Xu H, Li Y, Huang X, Lin L, Chen Y. A signature of immune-related gene pairs predicts oncologic outcomes and response to immunotherapy in lung adenocarcinoma. Genomics. 2020; 112:4675-83. https://doi.org/10.1016/j.ygeno.2020.08.014 PMID: $\underline{32798715}$

21. Wang $\mathrm{S}, \mathrm{Xu} \mathrm{X}$. An Immune-Related Gene Pairs Signature for Predicting Survival in Glioblastoma. Front Oncol. 2021; 11:564960.

https://doi.org/10.3389/fonc.2021.564960 PMID:33859933

22. Pfannstiel C, Strissel PL, Chiappinelli KB, Sikic D, Wach S, Wirtz RM, Wullweber A, Taubert H, Breyer J, Otto W, Worst $\mathrm{T}$, Burger $\mathrm{M}$, Wullich $\mathrm{B}$, et al, and BRIDGE 
Consortium, Germany. The Tumor Immune Microenvironment Drives a Prognostic Relevance That Correlates with Bladder Cancer Subtypes. Cancer Immunol Res. 2019; 7:923-38.

https://doi.org/10.1158/2326-6066.CIR-18-0758

PMID:30988029

23. Long $X$, Hou $H$, Wang $X$, Liu $S$, Diao T, Lai $S$, Hu M, Zhang $S$, Liu $M$, Zhang $H$. Immune signature driven by ADT-induced immune microenvironment remodeling in prostate cancer is correlated with recurrence-free survival and immune infiltration. Cell Death Dis. 2020; 11:779.

https://doi.org/10.1038/s41419-020-02973-1 PMID:32951005

24. Vuong L, Kotecha RR, Voss MH, Hakimi AA. Tumor Microenvironment Dynamics in Clear-Cell Renal Cell Carcinoma. Cancer Discov. 2019; 9:1349-57. https://doi.org/10.1158/2159-8290.CD-19-0499 PMID:31527133

25. Maio M, Blank C, Necchi A, Di Giacomo AM, Ibrahim R, Lahn M, Fox BA, Bell RB, Tortora G, Eggermont AM. Neoadjuvant immunotherapy is reshaping cancer management across multiple tumour types: The future is now! Eur J Cancer. 2021; 152:155-64. https://doi.org/10.1016/i.ejca.2021.04.035 PMID:34107449

26. Kates M, Nirschl TR, Baras AS, Sopko NA, Hahn NM, Su X, Zhang J, Kochel CM, Choi W, McConkey DJ, Drake CG, Bivalacqua TJ. Combined Next-generation Sequencing and Flow Cytometry Analysis for an AntiPD-L1 Partial Responder over Time: An Exploration of Mechanisms of PD-L1 Activity and Resistance in Bladder Cancer. Eur Urol Oncol. 2021; 4:117-20.

https://doi.org/10.1016/i.euo.2019.01.017 PMID:31411999

27. Sharma P, Pachynski RK, Narayan V, Fléchon A, Gravis G, Galsky MD, Mahammedi H, Patnaik A, Subudhi SK, Ciprotti M, Simsek B, Saci A, Hu Y, et al. Nivolumab Plus Ipilimumab for Metastatic Castration-Resistant Prostate Cancer: Preliminary Analysis of Patients in the CheckMate 650 Trial. Cancer Cell. 2020; 38:489-99.e3. https://doi.org/10.1016/j.ccell.2020.08.007 PMID:32916128

28. Ruiz de Porras V, Pardo JC, Notario L, Etxaniz O, Font A. Immune Checkpoint Inhibitors: A Promising Treatment Option for Metastatic Castration-Resistant Prostate Cancer? Int J Mol Sci. 2021; 22:4712.

https://doi.org/10.3390/ijms22094712

PMID: $\underline{3946818}$

29. Kamai T, Kijima T, Tsuzuki T, Nukui A, Abe H, Arai K, Yoshida KI. Increased expression of adenosine 2A receptors in metastatic renal cell carcinoma is associated with poorer response to anti-vascular endothelial growth factor agents and anti-PD-1/AntiCTLA4 antibodies and shorter survival. Cancer Immunol Immunother. 2021; 70:2009-21.

https://doi.org/10.1007/s00262-020-02843-x PMID:33416945

30. Chu G, Xu T, Zhu G, Liu S, Niu H, Zhang M. Identification of a Novel Protein-Based Signature to Improve Prognosis Prediction in Renal Clear Cell Carcinoma. Front Mol Biosci. 2021; 8:623120.

https://doi.org/10.3389/fmolb.2021.623120

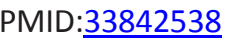

31. Gorin MA, Verdone JE, van der Toom E, Bivalacqua TJ, Allaf ME, Pienta KJ. Circulating tumour cells as biomarkers of prostate, bladder, and kidney cancer. Nat Rev Urol. 2017; 14:90-7.

https://doi.org/10.1038/nrurol.2016.224 PMID:27872478

32. Tölle A, Suhail S, Jung M, Jung K, Stephan C. Fatty acid binding proteins (FABPs) in prostate, bladder and kidney cancer cell lines and the use of IL-FABP as survival predictor in patients with renal cell carcinoma. BMC Cancer. 2011; 11:302.

https://doi.org/10.1186/1471-2407-11-302

PMID:21767383

33. Jungwirth N, Haeberle L, Schrott KM, Wullich B, Krause FS. Serotonin used as prognostic marker of urological tumors. World J Urol. 2008; 26:499-504. https://doi.org/10.1007/s00345-008-0285-9 PMID:18581119

34. Li B, Cui Y, Diehn M, Li R. Development and Validation of an Individualized Immune Prognostic Signature in Early-Stage Nonsquamous Non-Small Cell Lung Cancer. JAMA Oncol. 2017; 3:1529-37. https://doi.org/10.1001/jamaoncol.2017.1609 PMID:28687838

35. Newman AM, Liu CL, Green MR, Gentles AJ, Feng W, Xu Y, Hoang CD, Diehn $M$, Alizadeh AA. Robust enumeration of cell subsets from tissue expression profiles. Nat Methods. 2015; 12:453-7.

https://doi.org/10.1038/nmeth.3337 PMID:25822800

36. Wang $X$, Ding $Y$, Wang J, Wu Y. Identification of the Key Factors Related to Bladder Cancer by IncRNA-miRNAmRNA Three-Layer Network. Front Genet. 2020; 10:1398. https://doi.org/10.3389/fgene.2019.01398 PMID:32047516

37. Heidenreich $A$, Bastian PJ, Bellmunt J, Bolla $M$, Joniau S, van der Kwast T, Mason M, Matveev V, Wiegel T, Zattoni F, Mottet N, and European Association of Urology. EAU guidelines on prostate cancer. Part II: Treatment of advanced, relapsing, 
and castration-resistant prostate cancer. Eur Urol. 2014; 65:467-79.

https://doi.org/10.1016/j.eururo.2013.11.002

PMID:24321502

38. Kelsey R. Kidney cancer: ccrcc1-4 classification for prediction of relapse. Nat Rev Urol. 2018; 15:205.

https://doi.org/10.1038/nrurol.2018.34

PMID:29508851

39. Roberts ME, Aynardi JT, Chu CS. Uterine leiomyosarcoma: A review of the literature and update on management options. Gynecol Oncol. 2018; 151:562-72.

https://doi.org/10.1016/j.ygyno.2018.09.010

PMID: $\underline{30244960}$

40. Shariat SF, Karakiewicz PI, Godoy G, Karam JA, Ashfaq $\mathrm{R}$, Fradet $\mathrm{Y}$, Isbarn $\mathrm{H}$, Montorsi $\mathrm{F}$, Jeldres $\mathrm{C}$, Bastian PJ, Nielsen ME, Müller SC, Sagalowsky AI, Lotan Y. Survivin as a prognostic marker for urothelial carcinoma of the bladder: a multicenter external validation study. Clin Cancer Res. 2009; 15:7012-9.

https://doi.org/10.1158/1078-0432.CCR-08-2554 PMID:19903782

41. Mo Q, Nikolos F, Chen F, Tramel Z, Lee YC, Hayashi K, Xiao J, Shen J, Chan KS. Prognostic Power of a Tumor Differentiation Gene Signature for Bladder Urothelial Carcinomas. J Natl Cancer Inst. 2018; 110:448-59. https://doi.org/10.1093/inci/djx243 PMID:29342309

42. Sikic D, Eckstein M, Wirtz RM, Jarczyk J, Worst TS, Porubsky S, Keck B, Kunath F, Weyerer V, Breyer J, Otto W, Rinaldetti S, Bolenz C, et al. FOXA1 Gene Expression for Defining Molecular Subtypes of Muscle-Invasive Bladder Cancer after Radical Cystectomy. J Clin Med. 2020; 9:994.

https://doi.org/10.3390/jcm9040994

PMID: $\underline{32252315}$

43. Gerke JS, Orth MF, Tolkach Y, Romero-Pérez L, Wehweck FS, Stein S, Musa J, Knott MM, Hölting TL, Li J, Sannino G, Marchetto A, Ohmura S, et al. Integrative clinical transcriptome analysis reveals TMPRSS2-ERG dependency of prognostic biomarkers in prostate adenocarcinoma. Int J Cancer. 2020; 146:2036-46.

https://doi.org/10.1002/ijc.32792

PMID:31732966

44. Wu CL, Schroeder BE, Ma XJ, Cutie CJ, Wu S, Salunga R, Zhang Y, Kattan MW, Schnabel CA, Erlander MG, McDougal WS. Development and validation of a 32gene prognostic index for prostate cancer progression. Proc Natl Acad Sci USA. 2013; 110:6121-6. https://doi.org/10.1073/pnas.1215870110 PMID:23533275

45. Zhao SG, Evans JR, Kothari V, Sun G, Larm A, Mondine $V$, Schaeffer EM, Ross AE, Klein EA, Den RB, Dicker AP,
Karnes RJ, Erho N, et al. The Landscape of Prognostic Outlier Genes in High-Risk Prostate Cancer. Clin Cancer Res. 2016; 22:1777-86.

https://doi.org/10.1158/1078-0432.CCR-15-1250 PMID:26631616

46. Liang T, Sang S, Shao Q, Chen C, Deng Z, Wang T, Kang Q. Abnormal expression and prognostic significance of EPB41L1 in kidney renal clear cell carcinoma based on data mining. Cancer Cell Int. 2020; 20:356.

https://doi.org/10.1186/s12935-020-01449-8 PMID:32760223

47. Yang CA, Huang HY, Yen JC, Chang JG. Prognostic Value of RNASEH2A-, CDK1-, and CD151-Related Pathway Gene Profiling for Kidney Cancers. Int J Mol Sci. 2018; 19:1586.

https://doi.org/10.3390/ijms19061586

PMID:29843367

48. Kim KM, Hussein UK, Bae JS, Park SH, Kwon KS, Ha SH, Park HS, Lee H, Chung MJ, Moon WS, Kang MJ, Jang KY. The Expression Patterns of FAM83H and PANX2 Are Associated With Shorter Survival of Clear Cell Renal Cell Carcinoma Patients. Front Oncol. 2019; 9:14. https://doi.org/10.3389/fonc.2019.00014 PMID: $\underline{30723706}$

49. Fu Y, Sun S, Bi J, Kong C, Yin L. A novel immunerelated gene pair prognostic signature for predicting overall survival in bladder cancer. BMC Cancer. 2021; 21:810.

https://doi.org/10.1186/s12885-021-08486-0 PMID:34266411

50. Zhou X, Qiu S, Jin D, Jin K, Zheng X, Yang L, Wei Q. Development and Validation of an Individualized Immune-Related Gene Pairs Prognostic Signature in Papillary Renal Cell Carcinoma. Front Genet. 2020; 11:569884.

https://doi.org/10.3389/fgene.2020.569884 PMID:33240321

51. Wong YN, Joshi K, Khetrapal $P$, Ismail $M$, Reading JL, Sunderland MW, Georgiou A, Furness AJ, Ben Aissa A, Ghorani E, Oakes T, Uddin I, Tan WS, et al. Urinederived lymphocytes as a non-invasive measure of the bladder tumor immune microenvironment. J Exp Med. 2018; 215:2748-59.

https://doi.org/10.1084/jem.20181003 PMID:30257862

52. Luo C, Chen J, Chen L. Exploration of gene expression profiles and immune microenvironment between high and low tumor mutation burden groups in prostate cancer. Int Immunopharmacol. 2020; 86:106709. https://doi.org/10.1016/i.intimp.2020.106709 PMID:32593155

53. Şenbabaoğlu Y, Gejman RS, Winer AG, Liu M, Van Allen 
EM, de Velasco G, Miao D, Ostrovnaya I, Drill E, Luna A, Weinhold N, Lee W, Manley BJ, et al. Erratum to: Tumor immune microenvironment characterization in clear cell renal cell carcinoma identifies prognostic and immunotherapeutically relevant messenger RNA signatures. Genome Biol. 2017; 18:46.

https://doi.org/10.1186/s13059-017-1180-8

PMID:28249590

54. Greten FR, Grivennikov SI. Inflammation and Cancer: Triggers, Mechanisms, and Consequences. Immunity. 2019; 51:27-41.

https://doi.org/10.1016/i.immuni.2019.06.025

PMID:31315034

55. Crusz SM, Balkwill FR. Inflammation and cancer: advances and new agents. Nat Rev Clin Oncol. 2015; 12:584-96.

https://doi.org/10.1038/nrclinonc.2015.105

PMID:26122183

56. Cassetta L, Pollard JW. Targeting macrophages: therapeutic approaches in cancer. Nat Rev Drug Discov. 2018; 17:887-904.

https://doi.org/10.1038/nrd.2018.169 PMID:30361552

57. Ngambenjawong C, Gustafson HH, Pun SH. Progress in tumor-associated macrophage (TAM)-targeted therapeutics. Adv Drug Deliv Rev. 2017; 114:206-21. https://doi.org/10.1016/j.addr.2017.04.010 PMID:28449873
58. Shi $Y R$, Xiong $K$, Ye $X$, Yang $P, W u ~ Z, Z u ~ X B$. Development of a prognostic signature for bladder cancer based on immune-related genes. Ann Transl Med. 2020; 8:1380.

https://doi.org/10.21037/atm-20-1102

PMID:33313125

59. Zheng X, Zhou X, Xu H, Jin D, Yang L, Shen B, Qiu S, Ai J, Wei Q. A Novel Immune-Gene Pair Signature Revealing the Tumor Microenvironment Features and Immunotherapy Prognosis of Muscle-Invasive Bladder Cancer. Front Genet. 2021; 12:764184. https://doi.org/10.3389/fgene.2021.764184 PMID:34899849

60. Zhang LH, Li LQ, Zhan YH, Zhu ZW, Zhang XP. Identification of an IRGP Signature to Predict Prognosis and Immunotherapeutic Efficiency in Bladder Cancer. Front Mol Biosci. 2021; 8:607090. https://doi.org/10.3389/fmolb.2021.607090 PMID:33937319

61. Tao Z, Zhang E, Li L, Zheng J, Zhao Y, Chen X. A united risk model of 11 immune-related gene pairs and clinical stage for prediction of overall survival in clear cell renal cell carcinoma patients. Bioengineered. 2021; 12:4259-77. https://doi.org/10.1080/21655979.2021.1955558 PMID:34304692 


\section{SUPPLEMENTARY MATERIALS}

\section{Supplementary Figures}

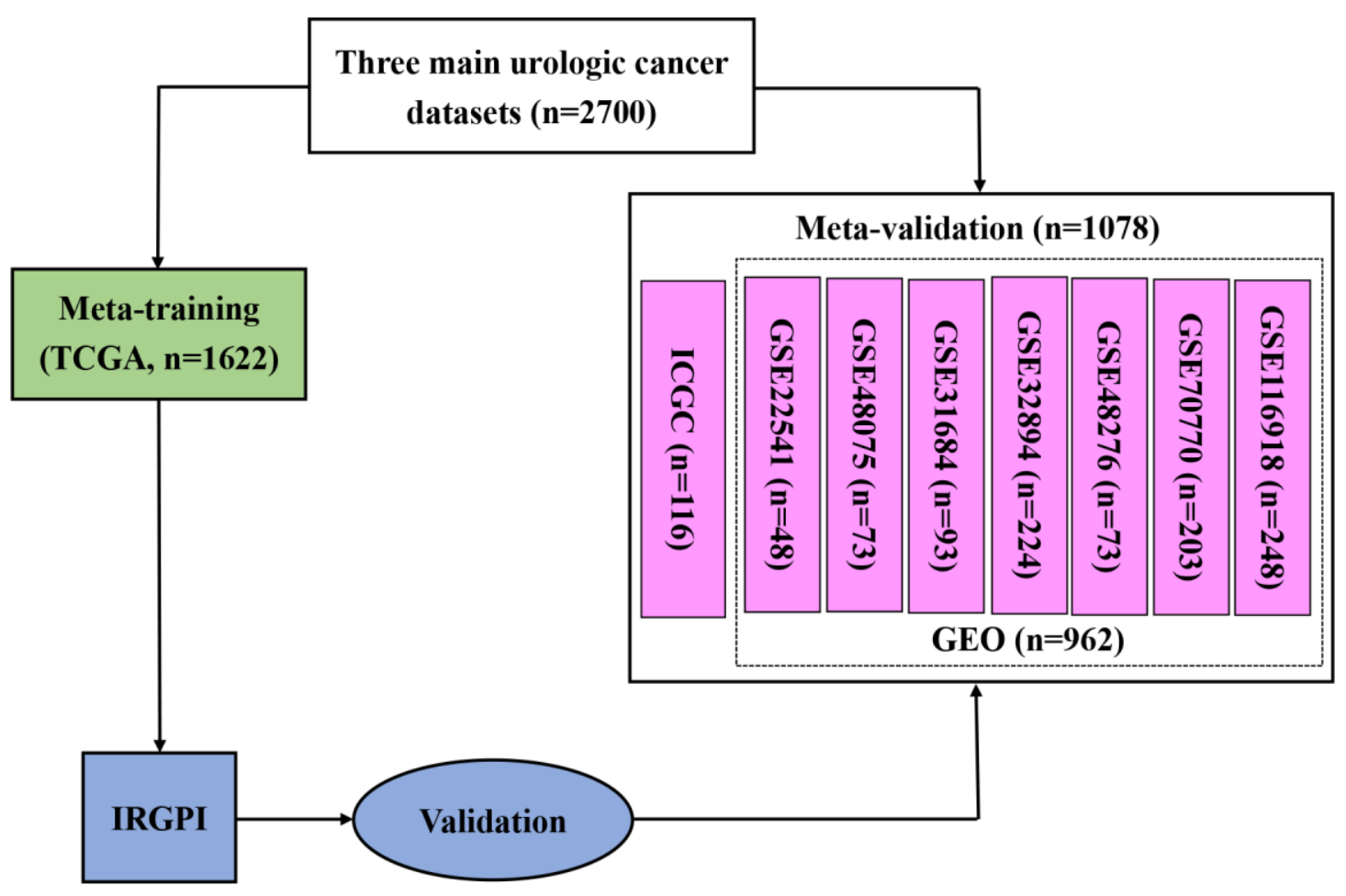

Supplementary Figure 1. Overview of the construction and validation of the immune-related gene pairs signature. Fourteen datasets were included in this study. Five TCGA datasets, including TCGA_BLCA (training cohort of bladder cancer), TCGA_PRAD (training cohort of prostate cancer), TCGA_KIRC, TCGA_KIRP and TCGA_KICH constituted the meta-training dataset. TCGA_KIRC, TCGA_KIRP and TCGA_KICH were combined for the kidney cancer cohort (training cohort of kidney cancer). Seven GEO datasets including GSE48075, GSE31684, GSE32894, GSE48276, GSE70770, GSE116918 and GSE22541, and two ICGC datasets, including ICGC_PRAD and ICGC_RECA, were merged to form a meta-validation dataset. GSE48075, GSE31684, GSE32894 and GSE48276 were combined in the validation dataset of bladder cancer (validation cohort of bladder cancer). GSE70770, GSE116918 and ICGC_PRAD were merged to form the validation dataset of prostate cancer (validation cohort of prostate cancer). GSE22541 and ICGC_RECA constituted the validation dataset of kidney cancer (validation cohort of kidney cancer). The meta-training dataset was used to build an immune-related gene pairs signature index (IRGPI). The IRGPI was verified on the meta-validation and independent validation datasets. 
A
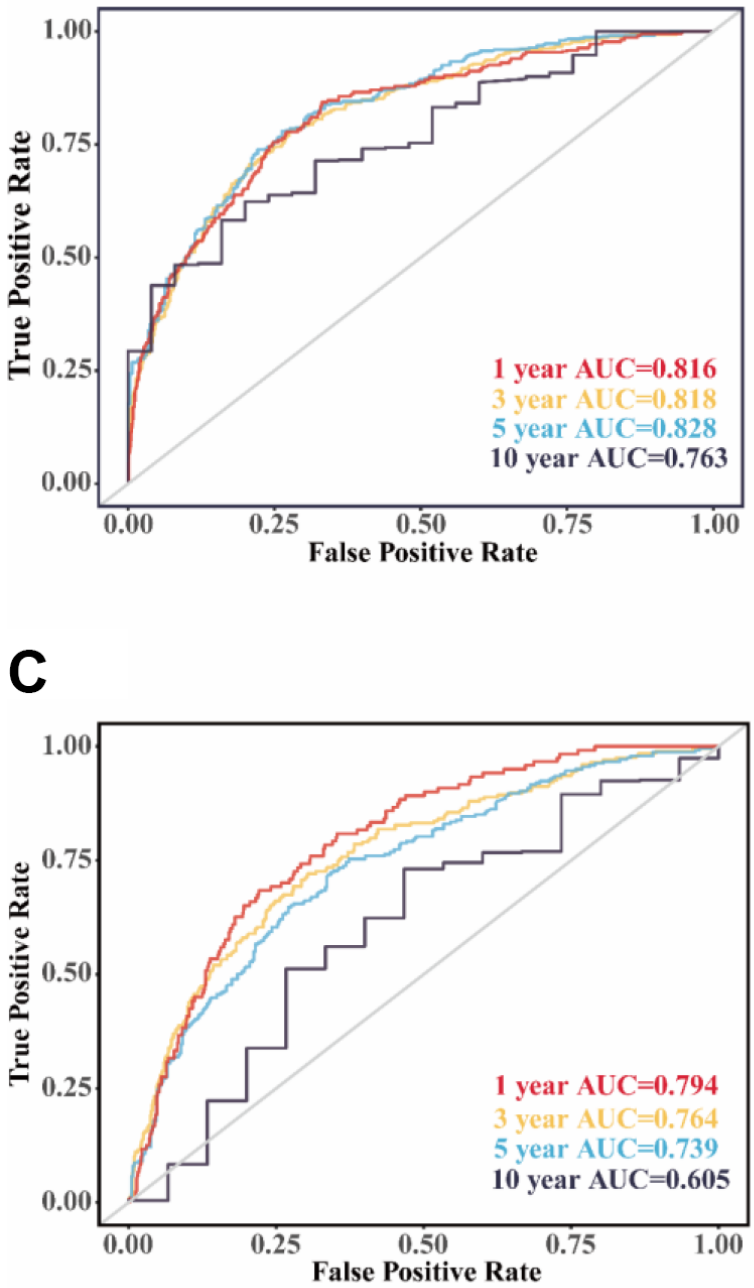

B

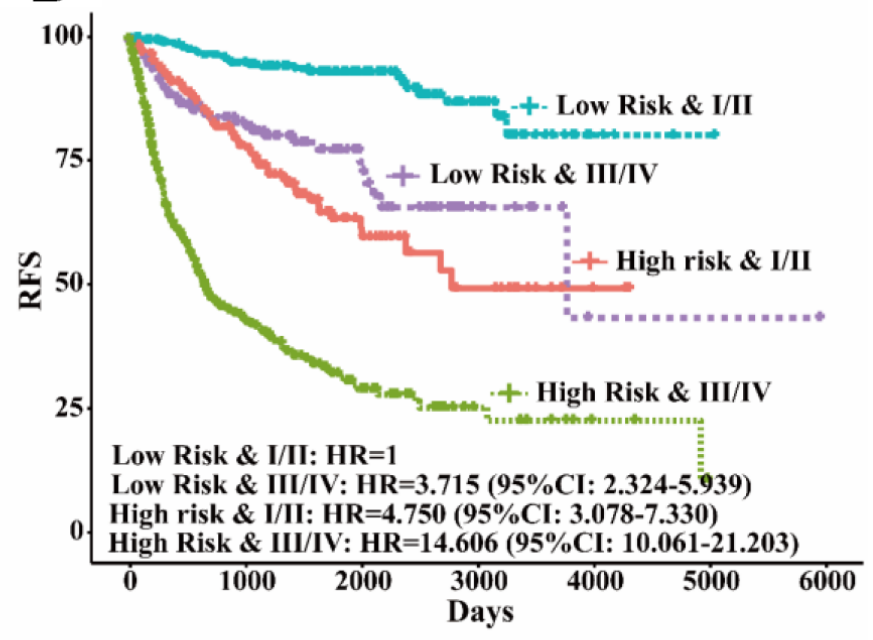

D

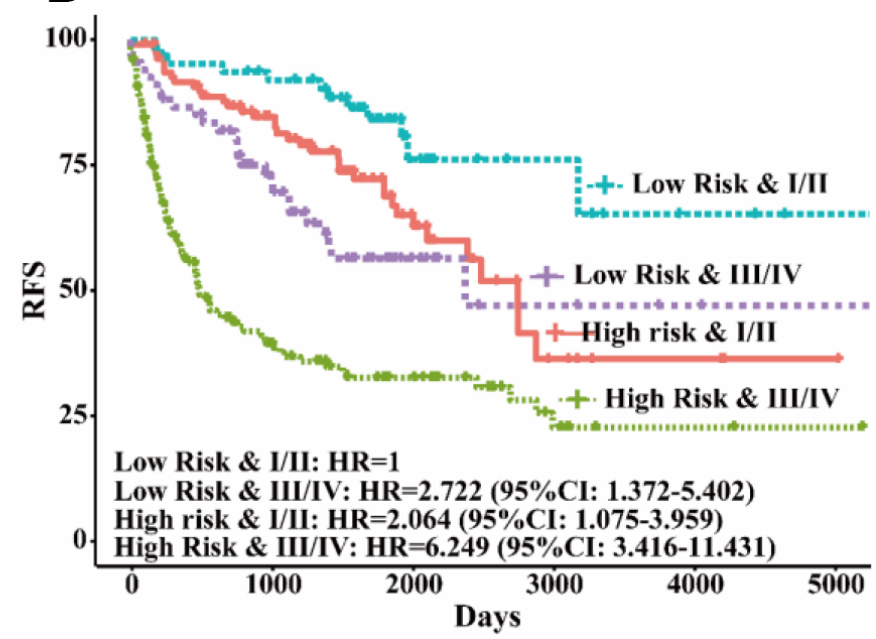

Supplementary Figure 2. Time-dependent ROC curves and Kaplan-Meier curves. (A) The time-dependent ROC curves of the IRGPI for 1-, 3-, 5- and 10-year RFS of patients in the meta-training cohort. (B) RFS among patients in the meta-training cohort stratified by IRGPI and tumor stage. (C) Time-dependent ROC curves of the IRGPI for 1-, 3-, 5- and 10-year RFS of patients in the meta-validation cohort. (D) RFS among patients in the meta-validation cohort stratified by IRGPI and tumor stage. 
A
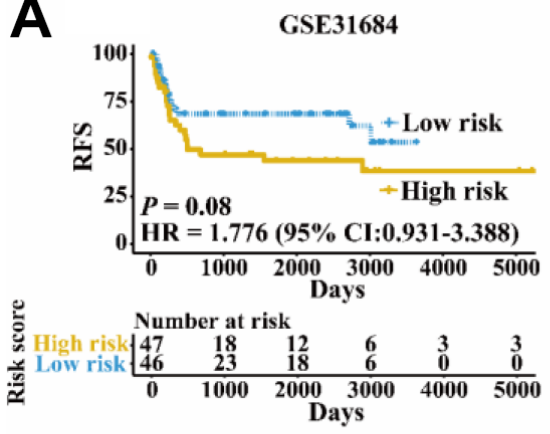

D

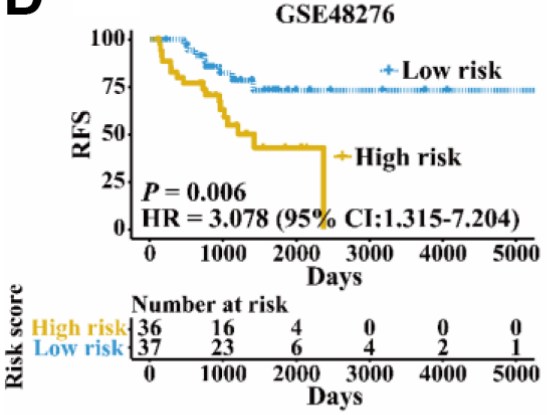

G

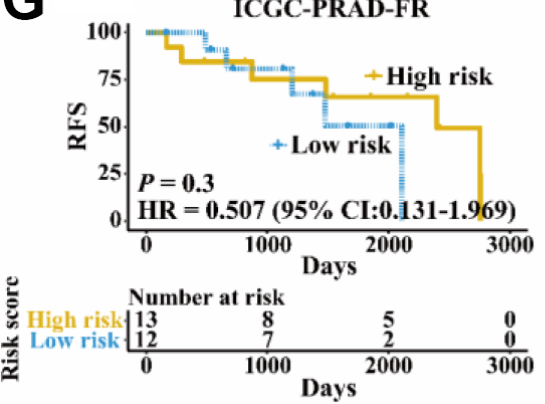

B

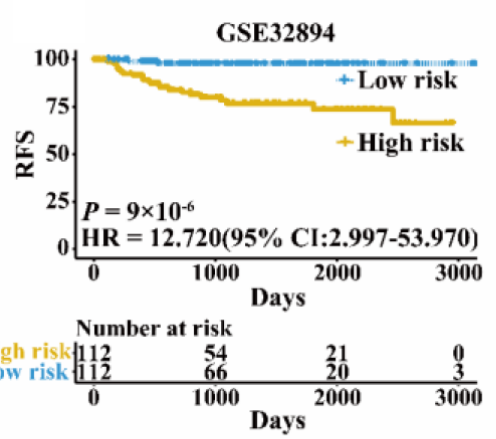

E

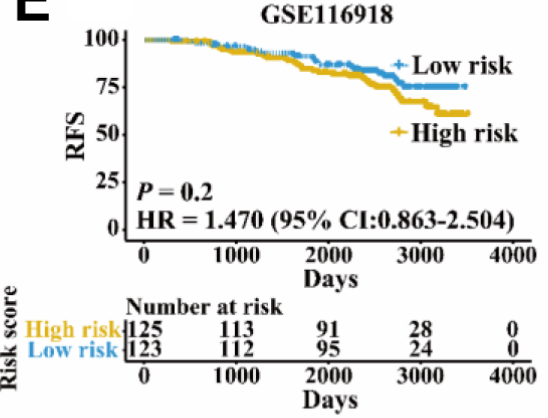

H

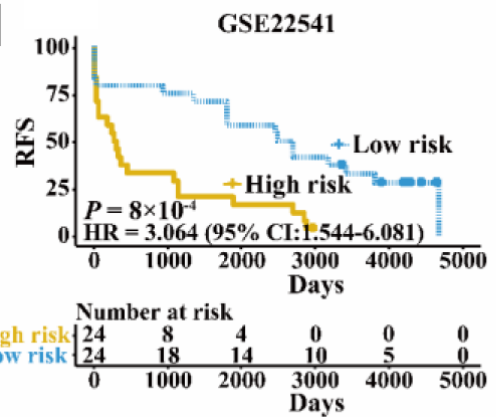

C

GSE48075

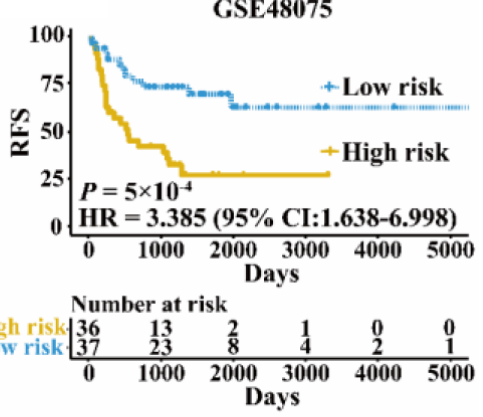

F

GSE70770
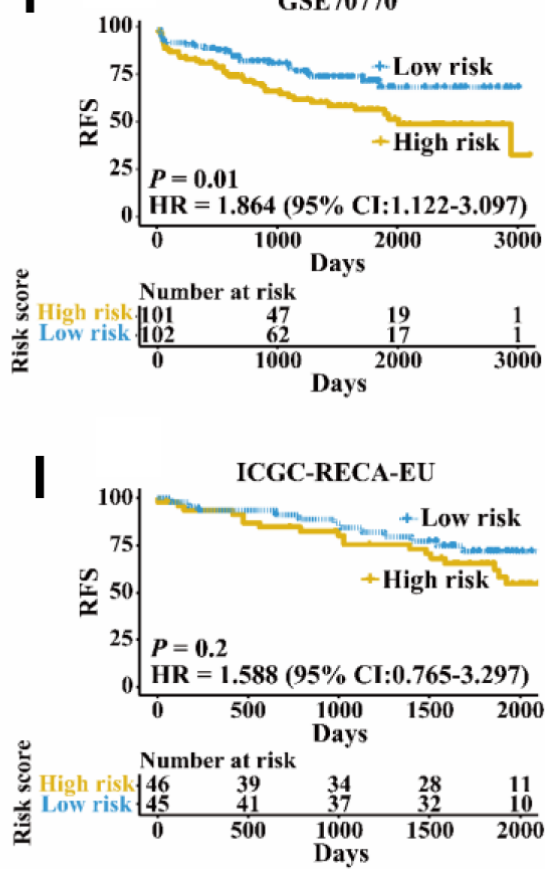

Supplementary Figure 3. Kaplan-Meier curves of patients in independent validation cohorts stratified by the IRGPI. (A) RFS among patients with bladder cancer in the GSE31684 cohort. (B) RFS among patients with bladder cancer in the GSE32894 cohort. (C) RFS among patients with bladder cancer in the GSE48075 cohort. (D) RFS among patients with bladder cancer in the GSE48276 cohort. (E) RFS among patients with prostate cancer in the GSE116918 cohort. (F) RFS among patients with prostate cancer in the GSE70770 cohort. (G) RFS among patients with prostate cancer in the ICGC-PRAD-FR cohort. (H) RFS among patients with kidney cancer in the GSE22541 cohort. (I) RFS among patients with kidney cancer in the ICGC-RECA-EU cohort. Hazard ratios (HRs) and 95\% Cls were for high vs low immune risk. p-values comparing risk groups were calculated with the log-rank test. 
A

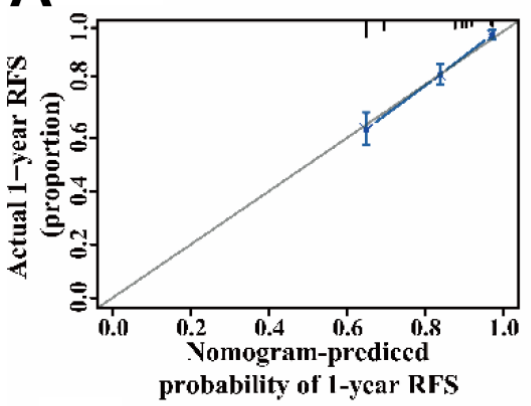

D

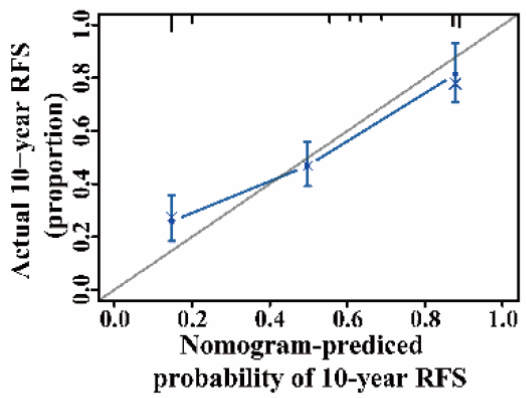

G

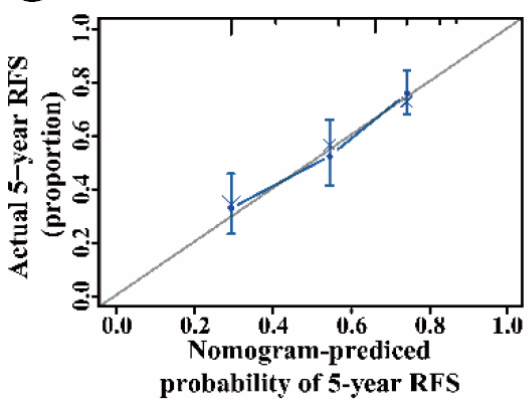

B

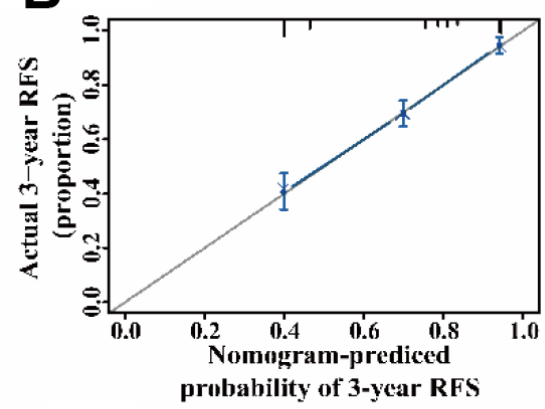

$\mathbf{E}$

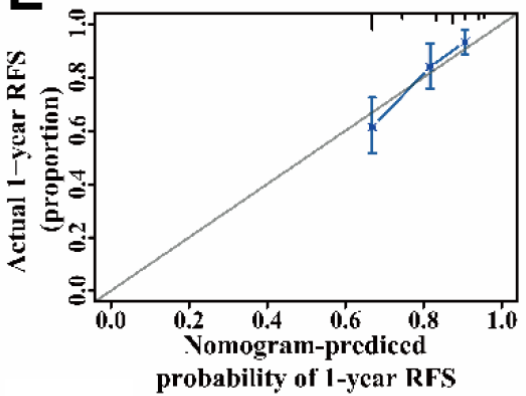

$\mathrm{H}$

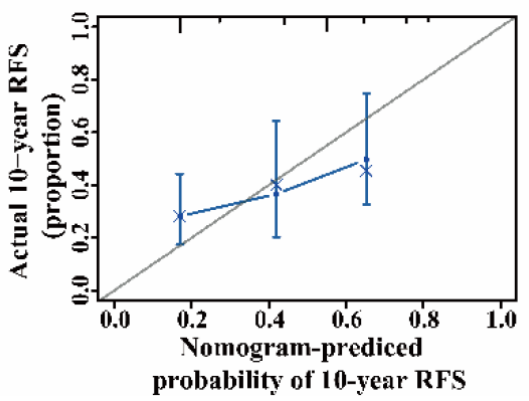

C

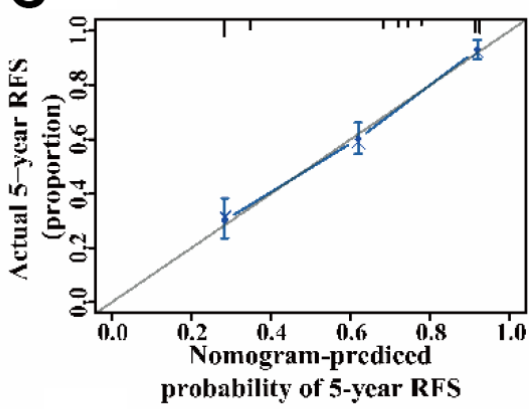

$\mathbf{F}$

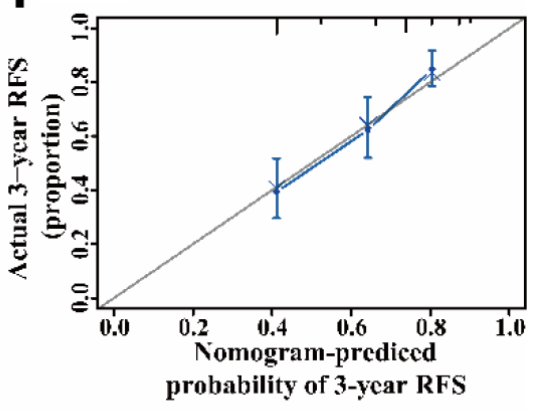

Supplementary Figure 4. Nomogram evaluation for predicting 1-, 3-, 5-, and 10-year RFS. (A-D) Calibration plots of the nomogram for predicting the probability of RFS at 1 (A), 3 (B), 5 (C) and 10 years (D) in the meta-training cohort. (E-H) Calibration plots of the nomogram for predicting the probability of RFS at 1 (E), $3(\mathbf{F}), 5(\mathbf{G})$ and 10 years $(\mathbf{H})$ in the meta-validation cohort. 


\section{Supplementary Tables}

Please browse Full Text version to see the data of Supplementary Table 4.

Supplementary Table 1. Details about the data sets used in this study.

\begin{tabular}{lcc}
\hline Accession number & Platform & Samples \\
\hline Urologic cancer & & $\mathbf{2 , 7 0 0}$ \\
Bladder Cancer & & $\mathbf{8 3 5}$ \\
TCGA & Illumina HiSeq & 372 \\
GSE48075 & Illumina HumanHT-12 V3.0 expression beadchip & 73 \\
GSE31684 & Affymetrix Human Genome U133 Plus 2.0 Array & 93 \\
GSE32894 & Illumina HumanHT-12 V3.0 expression beadchip & 224 \\
GSE48276 & Illumina HumanHT-12 WG-DASL V4.0 R2 expression & 73 \\
Prostate Cancer & beadchip & $\mathbf{8 8 8}$ \\
TCGA & & 412 \\
GSE70770 & Illumina HiSeq & 203 \\
GSE116918 & Illumina HumanHT-12 V4.0 expression beadchip \\
ICGC-PRAD-FR & Almac Diagnostics Prostate Disease Specific Array (DSA) & 248 \\
Kidney cancer & Illumina HiSeq & 25 \\
TCGA Kidney Clear Cell Carcinoma & & $\mathbf{9 7 7}$ \\
TCGA Kidney Papillary Cell Carcinoma & Illumina HiSeq & 503 \\
TCGA Kidney Chromophobe Carcinoma & Illumina HiSeq & 276 \\
GSE22541 & Illumina HiSeq & 59 \\
ICGC-RECA-EU & Affymetrix Human Genome U133 Plus 2.0 Array & 48 \\
\hline
\end{tabular}

Supplementary Table 2. Model information about the IRGPI.

\begin{tabular}{|c|c|c|c|c|c|c|}
\hline IRG 1 & Full name & Immune processes & IRG 2 & Full name & Immune processes & Coefficient \\
\hline FASLG & Fas ligand & Multiple & FGF5 & fibroblast growth factor 5 & Cytokines & 0.611523169778837 \\
\hline JAK2 & Janus kinase 2 & Antimicrobials & IL15RA & $\begin{array}{c}\text { interleukin } 15 \text { receptor } \\
\text { subunit alpha }\end{array}$ & Multiple & 0.333805374153765 \\
\hline IREB2 & $\begin{array}{l}\text { iron responsive element } \\
\text { binding protein } 2\end{array}$ & Antimicrobials & NEDD4 & $\begin{array}{l}\text { NEDD4 E3 ubiquitin } \\
\text { protein ligase }\end{array}$ & Antimicrobials & 0.557427035341619 \\
\hline BST2 & $\begin{array}{c}\text { bone marrow stromal cell } \\
\text { antigen } 2\end{array}$ & Antimicrobials & SLC40A1 & $\begin{array}{c}\text { solute carrier family } 40 \\
\text { member } 1\end{array}$ & Antimicrobials & -0.343127675750891 \\
\hline BIRC5 & $\begin{array}{l}\text { baculoviral IAP repeat } \\
\text { containing } 5\end{array}$ & Antimicrobials & IL11RA & $\begin{array}{l}\text { interleukin } 11 \text { receptor } \\
\text { subunit alpha }\end{array}$ & Multiple & 0.120504722606519 \\
\hline IL5RA & $\begin{array}{c}\text { interleukin } 5 \text { receptor subunit } \\
\text { alpha }\end{array}$ & Multiple & PDIA2 & $\begin{array}{c}\text { protein disulfide } \\
\text { isomerase family A } \\
\text { member } 2\end{array}$ & $\begin{array}{l}\text { Antigen_Processing_ } \\
\text { and_Presentation }\end{array}$ & 0.342856072023345 \\
\hline RSAD2 & $\begin{array}{c}\text { radical S-adenosyl methionine } \\
\text { domain containing } 2\end{array}$ & Antimicrobials & IL13RA2 & $\begin{array}{l}\text { interleukin } 13 \text { receptor } \\
\text { subunit alpha } 2\end{array}$ & Multiple & 0.678808880744686 \\
\hline BIRC5 & $\begin{array}{l}\text { baculoviral IAP repeat } \\
\text { containing } 5\end{array}$ & Antimicrobials & NR4A3 & $\begin{array}{c}\text { nuclear receptor } \\
\text { subfamily } 4 \text { group A } \\
\text { member } 3\end{array}$ & Cytokine_Receptors & -0.291520461858733 \\
\hline CXCL5 & $\begin{array}{c}\mathrm{C}-\mathrm{X}-\mathrm{C} \text { motif chemokine ligand } \\
5\end{array}$ & Multiple & PLAU & $\begin{array}{c}\text { plasminogen activator, } \\
\text { urokinase }\end{array}$ & Multiple & -0.806211590266488 \\
\hline PDGFRA & $\begin{array}{l}\text { platelet derived growth factor } \\
\text { receptor alpha }\end{array}$ & Multiple & GNAI1 & $\begin{array}{l}\text { G protein subunit } \\
\text { alpha i1 }\end{array}$ & Antimicrobials & -0.279543844347446 \\
\hline IL21R & interleukin 21 receptor & Multiple & KLRD1 & $\begin{array}{l}\text { killer cell lectin like } \\
\text { receptor D1 }\end{array}$ & Multiple & -0.280214943593435 \\
\hline FABP3 & fatty acid binding protein 3 & Antimicrobials & LTB4R & leukotriene B4 receptor & Multiple & 0.194642442980463 \\
\hline IFIH1 & $\begin{array}{l}\text { interferon induced with } \\
\text { helicase } \mathrm{C} \text { domain } 1\end{array}$ & Antimicrobials & IL1RAP & $\begin{array}{l}\text { interleukin } 1 \text { receptor } \\
\text { accessory protein }\end{array}$ & Multiple & 0.185869442713303 \\
\hline
\end{tabular}




\begin{tabular}{|c|c|c|c|c|c|c|}
\hline BIRC5 & $\begin{array}{l}\text { baculoviral IAP repeat } \\
\text { containing } 5\end{array}$ & Antimicrobials & MAP3K8 & $\begin{array}{c}\text { mitogen-activated } \\
\text { protein kinase kinase } \\
\text { kinase } 8\end{array}$ & $\begin{array}{l}\text { TCRsignaling } \\
\text { Pathway }\end{array}$ & -0.129389559702631 \\
\hline BIRC5 & $\begin{array}{l}\text { baculoviral IAP repeat } \\
\text { containing } 5\end{array}$ & Antimicrobials & SEMA3F & semaphorin $3 \mathrm{~F}$ & Multiple & -0.072138438403510 \\
\hline IL1RAP & $\begin{array}{l}\text { interleukin } 1 \text { receptor accessory } \\
\text { protein }\end{array}$ & Multiple & NR3C2 & $\begin{array}{c}\text { nuclear receptor } \\
\text { subfamily } 3 \text { group C } \\
\text { member } 2\end{array}$ & $\begin{array}{l}\text { Cytokine_- } \\
\text { Receptors }\end{array}$ & $\begin{array}{c}- \\
0.0912124340222771\end{array}$ \\
\hline SEMA7A & $\begin{array}{c}\text { semaphorin 7A } \\
\text { (John Milton Hagen } \\
\text { blood group) }\end{array}$ & Multiple & SECTM1 & $\begin{array}{c}\text { secreted and } \\
\text { transmembrane } 1\end{array}$ & Cytokines & -0.343147031348337 \\
\hline IL20RB & $\begin{array}{c}\text { interleukin } 20 \text { receptor subunit } \\
\text { beta }\end{array}$ & Multiple & S100A8 & $\begin{array}{l}\text { S100 calcium binding } \\
\text { protein A8 }\end{array}$ & Antimicrobials & -0.396800456172257 \\
\hline LIFR & LIF receptor subunit alpha & Cytokine_Receptors & JAG1 & $\begin{array}{c}\text { jagged canonical Notch } \\
\text { ligand } 1\end{array}$ & Cytokines & 0.645240142760529 \\
\hline BIRC5 & $\begin{array}{l}\text { baculoviral IAP repeat } \\
\text { containing } 5\end{array}$ & Antimicrobials & MICB & $\begin{array}{c}\text { MHC class I } \\
\text { polypeptide-related } \\
\text { sequence B }\end{array}$ & Multiple & -0.071431251596447 \\
\hline BIRC5 & $\begin{array}{l}\text { baculoviral IAP repeat } \\
\text { containing } 5\end{array}$ & Antimicrobials & TNFRSF10A & $\begin{array}{c}\text { TNF receptor } \\
\text { superfamily member } \\
10 \mathrm{a}\end{array}$ & Multiple & $\begin{array}{c}- \\
0.0734371636311053\end{array}$ \\
\hline CCL22 & C-C motif chemokine ligand 22 & Multiple & GREM1 & $\begin{array}{l}\text { gremlin 1, DAN family } \\
\text { BMP antagonist }\end{array}$ & Cytokines & 0.279290394701392 \\
\hline FGF12 & fibroblast growth factor 12 & Cytokines & TNFSF4 & $\begin{array}{l}\text { TNF superfamily } \\
\text { member } 4\end{array}$ & Multiple & 0.379557014519608 \\
\hline IL13RA2 & $\begin{array}{c}\text { interleukin } 13 \text { receptor subunit } \\
\text { alpha } 2\end{array}$ & Multiple & MPL & $\begin{array}{l}\text { MPL proto-oncogene, } \\
\text { thrombopoietin receptor }\end{array}$ & Cytokine_Receptors & -0.17903152209123 \\
\hline PCSK1 & $\begin{array}{l}\text { proprotein convertase } \\
\text { subtilisin/kexin type } 1\end{array}$ & Antimicrobials & NUDT6 & nudix hydrolase 6 & Cytokines & $\begin{array}{c}- \\
0.0916418175539433\end{array}$ \\
\hline
\end{tabular}

Supplementary Table 3. Univariate and multivariate analyses of prognostic factors in terms of RFS.

\begin{tabular}{|c|c|c|c|c|c|}
\hline \multirow{2}{*}{ Datasets } & \multirow{2}{*}{ Variable } & \multicolumn{2}{|c|}{ Univariate analysis } & \multicolumn{2}{|c|}{ Multivariate analysis* } \\
\hline & & HR $(95 \%$ CI $)$ & $P$ Value & HR $(95 \%$ CI $)$ & $P$ Value \\
\hline \multirow{4}{*}{ Meta-training } & Age & $1.56(1.28-1.90)$ & $1.35 \times 10^{-5}$ & $1.18(0.96-1.45)$ & 0.11 \\
\hline & Gender & $1.07(0.86-1.34)$ & 0.536 & - & - \\
\hline & Stage & $5.05(4.00-6.38)$ & $<2 \times 10^{-16}$ & $3.22(2.52-4.11)$ & $<2 \times 10^{-16}$ \\
\hline & Immune risk & $6.08(4.75-7.77)$ & $<2 \times 10^{-16}$ & $4.22(3.23-5.52)$ & $<2 \times 10^{-16}$ \\
\hline \multirow{4}{*}{ Meta-validation } & Age & $1.50(1.05-2.15)$ & 0.0279 & $1.36(0.91-2.03)$ & 0.135771 \\
\hline & Gender & $0.99(0.69-1.42)$ & 0.948 & - & - \\
\hline & Stage & $2.96(2.12-4.14)$ & $2.01 \times 10^{-10}$ & $2.94(2.02-4.29)$ & $1.82 \times 10^{-8}$ \\
\hline & Immune risk & $2.12(1.55-2.91)$ & $2.57 \times 10^{-6}$ & $2.15(1.45-3.19)$ & 0.000149 \\
\hline
\end{tabular}

*Age, stage and immune risk were adjusted in multivariate analysis.

Supplementary Table 4. The significant biological processes enriched by genes consisted in the IRGPI. 